A CONCEPT PLAN FOR KENNEDY MOBILITY HUB:

ENVISIONING TRANSIT ORIENTED DEVELOPMENT IN TORONTO'S INNER SUBURBS

\author{
by \\ Kasper Oliver Koblauch \\ BA Honours Geography, Wilfrid Laurier University, 2011 \\ A Major Research Paper presented to Ryerson University \\ in partial fulfilment of the requirements for the degree of \\ Master of Planning \\ in \\ Urban Development
}

Toronto, Ontario, Canada, 2013

(c) Kasper Oliver Koblauch 2013 


\section{AUTHOR'S DECLARATION FOR ELECTRONIC SUBMISSION OF A MRP}

I hereby declare that I am the sole author of this MRP. This is a true copy of the MRP, including any required final revisions.

I authorize Ryerson University to lend this MRP to other institutions or individuals for the purpose of scholarly research

I further authorize Ryerson University to reproduce this MRP by photocopying or by other means, in total or in part, at the request of other institutions or individuals for the purpose of scholarly research.

I understand that my MRP may be made electronically available to the public. 


\title{
A Concept Plan for Kennedy Mobility Hub: \\ Envisioning Transit Oriented Development in Toronto's Inner Suburbs
}

(c) Kasper Oliver Koblauch 2013

Master of Planning

in

Urban Development

Ryerson University

\begin{abstract}
This project presents a concept plan and vision for Kennedy Mobility Hub in Toronto, Ontario. The concept plan seeks to achieve six project goals, which are informed by a literature review, policy review, and context review. The goals are: to increase residential and employment density; achieve a more complete mix of transit-supportive land uses; replace all surface parking currently on developable public lands; improve the pedestrian and cyclist experience; expand greenspace; and ensure seamless transit mobility. The concept plan proposes extensive changes to the project area including mid- and high-rise development on all publicly owned surface parking lands. A number of new and extended roads are proposed to increase the area's permeability and facilitate development.

Residential and employment densities for hypothetical development sites are calculated and discussed. The project highlights some of the pragmatic planning challenges, and potential solutions, associated with retrofitting commuter parking nodes to become transit- and pedestrian-oriented urban environments.
\end{abstract}




\section{Acknowledgements}

I would like to extend my sincere gratitude to my supervisor, Dr. Raktim Mitra, and my second reader, David Phalp. Without their generously provided time and guidance, this project would not have been possible. 


\section{Dedication}

To Niels Van Miltenburg; Andrew Morito-Karn; Conor Oberst; and my family. 


\section{Contents}

Chapter 1: Introduction 1

1.1 Introduction 1

1.2 Outline 2

Chapter 2: Literature Review 4

2.1 Introduction 4

2.2 TOD, What Should it Achieve? $\quad 4$

$\begin{array}{ll}2.3 \text { Density } & 7\end{array}$

2.4 Distance 8

2.5 Land Use Diversity 8

2.6 Design 9

$\begin{array}{ll}2.7 \text { Parking } & 11\end{array}$

2.8 Conclusion 12

Chapter 3: Policy Review 13

3.1 Introduction 13

3.2 Provincial Policy Statement, 2005

3.3 Growth Plan for the Greater Golden Horseshoe, 2006

3.4 City of Toronto Official Plan, 2010

3.5 The Big Move Regional Transportation Plan, 2008

3.6 The Mobility Hub Guidelines, 2011

$\begin{array}{ll}3.7 \text { Conclusion } & 17\end{array}$ 
Chapter 4: Kennedy Mobility Hub Context 19

4.1 Introduction 19

4.2 Present Role in Toronto's Transportation System 19

4.3 Future Role in Toronto's Transportation System 21

$\begin{array}{ll}\text { 4.4 Historical Context } & 21\end{array}$

4.5 Site Function 23

4.6 Surrounding Context and Characteristics 24

4.6.1 Parking 24

4.6.2 Built Form $\quad 25$

4.6.3 Gatineau Hydro Corridor $\quad 25$

4.6.4 Eglinton Avenue Bridge $\quad 26$

4.6.5 Land Use $\quad 26$

4.6.6 Parkland and Open-Space $\quad 26$

4.8 Local Demographics 28

4.9 Residential and Employment Density 28

4.10 Context Review Conclusion 28

Chapter 5: Project Parameters 30

5.1 Defining the Mobility Hub Study Area 30

5.2 Project Assumptions 32

5.3 Project Goals 32

Chapter 6: Concept Plan for Kennedy Mobility Hub 36

6.1 Introduction 36 
6.2 Site Functionality: Street Network 37

6.3 Site Functionality: Pedestrian Access Points 39

6.4 Site Functionality: Transit $\quad 41$

6.5 Bicycle Functionality $\quad 43$

6.6 Parking Strategy $\quad 43$

6.7 Parkland and Recreational Space $\quad 46$

6.8 Kennedy Station Building 48

6.9 Eglinton Avenue Bridge 49

Chapter 7: Potential Development Areas 53

7.1 Introduction 53

7.2 Land Use 53

$\begin{array}{ll}\text { 7.3 Design } & 55\end{array}$

$\begin{array}{ll}\text { 7.4 Development Area A } & 57\end{array}$

7.5 Development Area B 58

7.6 Development Area C 59

7.7 Development Area D 60

7.8 Development Area E 61

$\begin{array}{ll}\text { 7.9 Density } & 62\end{array}$

Chapter 8: Discussion \& Conclusion 64

8.1 Goal Reflection 64

$\begin{array}{ll}\text { 8.2 Conclusion } & 67\end{array}$

$\begin{array}{ll}\text { References } & 74\end{array}$ 


\section{List of Figures}

$\begin{array}{ll}\text { Figure 4.1 Station and Surrounding Context } & 20\end{array}$

Figure 4.2 Kennedy Station Transit Context 20

Figure 4.3 Kennedy Station Area Before Stn. Construction 22

Figure 4.4 Kennedy Station Area as is Today 22

Figure 4.5 Kennedy Station Current Transit Functionality 23

Figure 4.6 TTC Operated Parking 24

Figure 4.7 Gatineau Hydro Corridor and Trail 25

$\begin{array}{ll}\text { Figure 4.8 Land Use Surrounding Kennedy Station } & 27\end{array}$

Figure 4.9 Gatineau Trail Terminus at Eglinton Ave. 27

Figure 4.10 Gatineau Trail $\quad 27$

Figure 5.1 Project Primary, Secondary and Tertiary Zones 31

Figure 5.2 Underground Transit Connections Present and Planned 32

Figure 6.1 Kennedy Existing 36

Figure 6.2 Kennedy Envisioned 36

Figure 6.3 Envision Changes to Road Network 37

Figure 6.4 Alternative to New Road A 38

$\begin{array}{ll}\text { Figure } 6.5 \text { Station Entrances } & 40\end{array}$

$\begin{array}{ll}\text { Figure 6.6 Present Bus Functionality } & 41\end{array}$

Figure 6.7 Adjusted Bus Functionality $\quad 42$

Figure 6.8 Envisioned Surface and Underground Parking 45

Figure 6.9 Envisioned Gatineau Trail Extension 47

Figure 6.10 Conceptual Kennedy Station Building 49

$\begin{array}{ll}\text { Figure 6.11 Eglinton Bridge } & 50\end{array}$ 
$\begin{array}{ll}\text { Figure 6.12 Cyclist on Bridge } & 50\end{array}$

Figure 6.13 Skyline Seen From Bridge $\quad 50$

Figure 6.14 Eglinton Bridge $\quad 52$

Figure 6.15 Eglinton Overpass as Envisioned 52

Figure 7.1 Development Areas Key Map 56

Figure 7.2 Development Area A $\quad 57$

Figure 7.3 Development Area B 58

Figure 7.4 Development Area C 59

Figure 7.5 Development Area D 60

$\begin{array}{ll}\text { Figure 7.6 Development Area E } & 61\end{array}$

\section{List of Appendices}

Appendix 1: Site Visits 68

Appendix 2: Concept Plan Density Calculations 69 


\section{Chapter 1: Introduction}

With the unveiling of its Big Move Regional Transportation Plan (RTP) in 2008, Metrolinx (the regional transit authority), put forth a bold vision to expand and enhance the tired transit infrastructure in the Greater Toronto and Hamilton Area (GTHA). A critical component of the RTP is the establishment of 51 transit-connected "mobility hubs" across the region. The mobility hub concept, reflecting the principles of Transit Oriented Development (TOD), envisions dense and mixed use nodes centred on higher-order transit stations. The mobility hub concept represents an exciting movement towards sustainable and liveable communities, and begins to address the salient issues of congestion, air pollution, and losses to economic productivity attributed to gridlock.

Since the RTP's release in 2008, a number of mobility hub studies have been completed by municipalities in concert with associated transit providers. Metrolinx also released its Mobility Hub Guidelines (the Guidelines) in 2011 to help illustrate, inspire, and guide the mobility hub concept. While progress is being made, physical implementation has been limited, leaving some uncertainty over how the mobility hub vision will take shape on the ground.

While many designated mobility hub areas already exhibit the foundations of transit- and pedestrian- supportiveness, others, such as inner-suburban commuter nodes, are typified by automobile-oriented design, an abundance of surface parking, and low residential and employment densities. This project will explore mobility hub implementation at these innersuburban nodes through the creation of a concept plan for Kennedy Mobility Hub.

Kennedy Mobility Hub, located in the pre-amalgamation City of Scarborough, is the BloorDanforth subway line's eastern terminus and holds further significance as the future terminus for two currently funded light rail projects slated for completion by 2020 . This 
mobility hub exhibits a number of opportune assets such as large areas of publicly owned land and privately owned mixed use properties at its core, which both hold great potential for redevelopment. At the same time, numerous infrastructural and environmental barriers will need to be overcome in order to fully realize the area's potential. With extensive construction and re-development at Kennedy Mobility Hub anticipated as part of the forthcoming transit investments, considerations of how best to capitalize upon the area's assets and overcome barriers are very timely. Kennedy Mobility Hub presents an opportunity to further a wide range of land use and transportation planning objectives as well as set the tone and pace for subsequent inner-suburban mobility hub re-development in the GTHA.

\subsection{Outline}

This project begins with an integrative literature review in order to understand the current state of professional practice and necessary considerations when planning for a mobility hub. Following the literature review, an in-depth policy review is undertaken in Chapter Three to distil the policy direction on the subject and considerations that must be accounted for when envisioning changes to the site. Although this project is conceptual, proposals for the site are intended to be grounded in a realistic policy framework. Chapter Four contains a context review of the site and its surroundings, the associated characteristics, constraints and function. This review is based upon field visits to the site, as well as historical and demographic research.

The insights gained from the literature review, policy review, and context review inform a list of goals that the concept plan strives to achieve. These are presented along with study parameters and study boundaries in Chapter Six. With study boundaries established and goals in mind, a conceptual site plan is presented for the primary zone in Chapter Seven. The chapter will discuss the concept plan's features and functionality, contrasting with what 
exists presently. This is followed by an overview of the proposed development sites in Chapter Eight and associated density analysis. The project concludes by reflecting on the goals established Chapter Six and discussing the degree to which these were achieved, and what conclusions can be drawn from the project's outcomes. 


\section{Chapter 2: Literature Review}

\subsection{Introduction}

An exercise such as mobility hub planning necessitates a wide range of considerations. As its starting point, the review will consider the higher-level goals and potential of TOD as envisaged by some of the topic's principal scholars. The focus will then narrow in to what are commonly called the D's or dimensions of TOD: density, distance, diversity, and design (Cervero, 1997; Belzer and Autler, 2002; TCRP, 2004). The final section will examine parking, a critical consideration when planning for a suburban mobility hub such as Kennedy, which features extensive commuter parking. The literature review will be used in conjunction with the policy review, and review of local context to determine a set of planning goals for Kennedy Mobility Hub.

\subsection{TOD What Should it Achieve?}

The emergence of the TOD paradigm has been accompanied by a healthy body of literature addressing TOD's normative purpose. Peter Calthorpe, generally recognized to have codified the TOD paradigm in the late 1980's (Carlton, 2007) describes the concept as:

Moderate and high-density housing, along with complementary public uses, jobs, retail, and services, are concentrated at mixed use developments at strategic points along the regional transit system (Calthorpe, 1993, pg.41)."

Calthorpe proposes TOD as a movement towards walkable and human scaled communities which address the undesirable by-products of suburbanization: congestion, pollution, isolation and economic hardship (Calthorpe, 1993). Another major contributor to this body of work, Robert Cervero, echoes Calthorpe's vision, seeing TOD as "a compact, mixed use community, centered around the transit station that, by design, invites residents, workers, and shoppers to drive their cars less and ride mass transit more" (TRCP, 2004,). By 
persuading and enabling people to leave their cars behind, Cervero opines that TOD has the potential to help reduce urban air pollution, relieve congestion, and improve pedestrian safety (Cervero and Guerra, 2011).

Belzer and Autler (2002) assert that TOD should, over all, strive to foster "livability." While anticipating the criticism that ideas of livability are subjective, the authors counter that a definition of livability can be reached based on "collective subjectivity." That is, what is widely recognized to be desirable. These facets of livability, according to the authors, include improved air quality; increased mobility choices; improved access to retail, recreation and cultural services; improved access to public space; improved health and safety, and strengthened economic opportunities. Belzer and Autler add that TOD's purpose is not to impose or circumscribe a new lifestyle, but rather present a choice, an alternative to the typical post-war pattern of development predicated on car ownership.

From the pictures of TOD painted by scholars such as Calthorpe (1993), Cervero and Guerra (2011), and Belzer and Autler (2002), two broad functions of TOD can be distilled. The first function of TOD is that of a transit node. That is, a place of easy access and connectivity between various forms of transportation. The second function is the place function, which refers to the community building ambitions of TOD, the creation of healthy, attractive, and livable places. Acknowledging these two separate functions is important because, as much literature points out, the place and node functions are often in direct opposition to one another (Filion, 2006; Belzer and Autler, 2002; Bertolini, 1998). Park-andride facilities are just one example of how the place and node functions can be opposed to one another. Parking provisions increase the station's functional capacity as an access point for transit (node function) but vast surface parking lots, which tend to act as barriers between the station and surrounding community, are unlikely to contribute to an attractive, desirable, or pedestrian supportive place (Belzer and Autler, 2002). A similar point can be made for rail corridors and fast-moving freeways. 
As Belzer and Autler (2002) point out, some actors in the station-area development process are inherently more interested in node functions while others are more interested in place. Ultimately, in the North American experience, the less tangible and less quantifiable placefunction seems to loose out (Belzer and Autler, 2002). Bertolini (1998) argues that transit stations are unique places in contemporary society where people still physically meet and this important function is nurtured by the perception that the station area is a good and desirable place. Ultimately, one of the most difficult and critical challenges of station area planning must be the reconciliation of node and place functions.

Creating a safe and inviting pedestrian environment (sometimes at odds with the node function discussed above) must be a paramount goal in TOD (Jones, 2006; Dunphy and Porter, 2006; Belzer and Autler, 2002; Calthorpe, 1993). This is true both because a pedestrian-scaled environment supports many of the higher-level goals discussed earlier, and because almost every transit user is also a pedestrian at some point on their trip (TCRP,2004; Morris, 1996). Each of the four "D" variables explored below - density, distance, diversity, and design - relates, at some level, to encouraging transit by reducing walk times or otherwise improving the pedestrian experience.

\subsection{Density}

High residential and employment density around transit nodes has long been recognized as key in achieving transit ridership goals (Cervero, 1997; Cervero and Guerra, 2011; TCRP, 2004; Ewing and Bartholomew, 2013). Since the transit operating cost per rider decreases with each additional user, costly transit investments become more economically feasible and justifiable the more riders they serve (Cervero and Guerra, 2011; Morris, 1996). Cervero and Guerra (2011) In analysing 24 light-rail systems in the United States, found that systems required station area densities of around 30 people per gross acre ( 75 people per hectare) to put them in the top one-quarter of cost-effective rail investments in the 
United States. Table 3.1 compares some minimum pedestrian and transit oriented design recommendations put forth by other scholars.

Table 3.1: Density Recommendations for TOD

\begin{tabular}{|l|l|l|l|}
\hline Source & People/Acre & People/Hectare & Author's Notes \\
\hline Calthorpe (1993) & $26-29$ & $64-97$ & \\
\hline Griffin (2004) & 42 & 103 & $\begin{array}{l}\text { Minimum to support } \\
\text { LRT }\end{array}$ \\
\hline Daisa (2003) & 28 & 69 & $\begin{array}{l}\text { Substantial increase in } \\
\text { transit use occurs at } \\
\text { this level of density }\end{array}$ \\
\hline
\end{tabular}

While it is clear that establishing higher density in TOD areas can bring people (ridership) to transit, a less obvious benefit is that dense urban environments can affect mode-share choice characteristics. This is because dense urban environments tend to bring origins and destinations closer together, thus encouraging walking and transit-use while discouraging driving (Cervero and Kockelman, 1997). Previous research conducted by The San Francisco Bay Area's Metropolitan Transit Authority, using data collected around 129 Bay Area rail stations, found density to be strongly correlated with train commuting. From the resulting equation, it was found, for example, that with densities of 10 units per acre, the proportion of rail commuters was $24.3 \%$ but if this density is doubled to 20 units per acre, the proportion of rail commuters jumps to $43.4 \%$ (TCRP, 2004).

Overall, the literature is unanimous on the importance of density. As density increases, so too does the cost effectiveness of transit infrastructure investments. Density targets, however, must be considered in the context of adjacent stable neighbourhoods, the capacity of local amenities, and the need for a desirable and locally accepted built-form. 


\subsection{Distance}

The distance of residents, jobs, and amenities from transit stations is another important factor in individual mode-share choices, and ultimately ridership numbers. The distance threshold within which people will typically walk to access transit is variable based on the mode of transit being accessed. A commonly agreed upon standard among scholars is that transit riders will typically walk approximately 400 meters to access bus and approximately 800 meters to reach rail transit (Ewing and Bartholomew, 2013; Griffin, 2004; Morris, 1996). Beyond these thresholds, willingness to walk to transit decreases sharply.

To gauge the importance of distance in an individual's mode choice, Cervero (1993) collected surveys from 2,500 San Francisco Bay area residents residing within $1 / 2$ mile (about 800 meters) of a rail station. The results showed that of those who had moved into the area from a location that was farther than 800 meters from transit (well beyond walking distance), 29 percent who used to commute by car had switched to rail transit. Ultimately, a mobility hub plan must strive to bring people, jobs, and services as close as comfortably possible to a transit.

\subsection{Land Use Diversity}

A diverse and well-planned mix of land use types surrounding station areas is widely recognized to be an important component of successful TOD. Scholars point out numerous benefits to a diverse and complementary mix of uses within walking distance of stations, an attribute Belzer and Autler (2002) label location efficiency. Location efficient station areas can meet the daily needs of commuters and create opportunities for commuters to tripchain, improving the convenience associated with transit (Cervero, 2006). A diverse mix of land uses also has the potential to generate off-peak and weekend transit use, establish an array of economic opportunities, and contribute to community vibrancy (Griffin, 2004; Cervero and Kockelman, 1997; Cervero, 2006; Morris, 1996; TCRP, 2004). By providing 
transit users with one-stop access to employment, child-care, restaurants, grocery stores, banking, etc., transit suddenly becomes very attractive.

Loo et al. (2010) studied the influence of commercial land use within station areas on higher-order transit patronage in New York City and Hong Kong. The results showed empirically that commercial floor area nearby stations was positively correlated with patronage. The results indicate the importance of meeting the commercial and convenience needs of transit users.

The need for commercial amenities close to stations is underscored in Beth Jones (2006) interviews with key informants regarding the necessary traits of future mobility hubs. A prominent theme is the need for a range of services around the station which allow people to "conduct the business of their daily lives while waiting or transferring..." (pg.25)

\subsection{Design}

Design can be said to play two important functions within TOD. The first is design's influence on transit access - how well and by what means the built environment persuades people to access transit. Noting that there is an extensive body of literature exploring the relationship between the built environment and travel choices, Cervero and Ewing (2010) undertook a meta-analysis on the topic, using data from over 50 previous studies. The meta-analysis sought to determine the effects of changes in design, density, and land use diversity on walking, transit use, and vehicle miles travelled respectively. While the authors found elasticities (ie, the percent change in travel behaviour for every one percent change in environment) to be low overall, the strongest associations for transit use were the number of intersections/street density as well as distance to transit. Intersections/street density was also found to have the highest weighted average elasticity on the choice to walk, another goal, and perhaps proxy-indicator, of transit use. The results indicate that street patterns are important considerations in planning for TOD. A highly connected and fine-grained street 
network, by providing fast and direct pedestrian connections, will encourage transit and walking (Cervero and Ewing, 2010).

Another way that transit users might access transit is by bicycle. Pucher (2009) points out that public transportation and cycling supportive design are mutually beneficial, with improvements in each encouraging use of the other. Bicycle supportive design extends the catchment area for transit beyond walking range at a lower cost than feeder bus service. Transit also provides a sometimes necessary alternative to cyclists when bad weather or disrepair prevents cycling. Furthermore, bicycle parking facilities are far less resource and space intensive than automobile park-and-ride facilities. Pucher (2009) identified bicycle lanes and pathways as well as sheltered and secure parking facilities as some of the most important design consideration in encouraging cycling.

Design also plays a fundamental role in the place function of TOD. While the place-making role of design is the subject of much discussion, most literature on the subject, as Belzer and Autler (2002) point out, is more descriptive than analytical. Design considerations important to the place-making function of TOD include achieving well-integrated and architecturally pleasing buildings and urban spaces (TCRP, 2004). Attractive and desirable places also pose a better chance of being well received by local residents, guarding against NIMBYism, a commonly cited hurdle facing TOD (TCRP, 2004).

\subsection{Parking}

The need to provide parking facilities for transit riders can stand in direct opposition to goals of designing walkable, compact, highly integrated, and attractive TOD. For this reason, parking is a critical and contentious piece of the mobility hub puzzle. In contemplating parking, both parking standards which accompany development, and park-and-ride facilities provided specifically for transit patrons must be considered. 
Cervero, Adkins, \& Sullivan, (2010) reviewed the relationship between transit and parking. The authors identified excessive parking standards as one of the factors most limiting the potential of TOD in the United States. These standards, which are opined to be out of date, are typically not adjusted downwards within TOD areas. It is pointed out that where, however, minimum parking standards are reduced, rates of car ownership fall appreciably, increasing the likelihood of transit ridership. In explanation of excessive parking standards, the authors point to political difficulties, namely fear from local business over insufficient parking and fear from local residents that parking will spill into their neighbourhoods.

The Victoria Transport Policy Institute (2012) analysed the costs and benefits of different forms of parking. It is revealed that although parking is often free to its user, as was the case until recently at many TTC owned lots (Bowman, 2012), parking carries a cost higher than is often realised, especially when considering the opportunity costs associated with this land use. Unstructured surface parking carries a price tag of approximately $\$ 10,000$ per space to construct plus maintenance, monitoring and the opportunity costs. Bicycle parking by contrast, only costs about one-twentieth this amount. Walking to transit, of course, eliminates the need for any parking altogether, furthering the argument in favour of prioritizing pedestrian access and the pedestrian realm.

Despite the significant costs of parking and its hindrance to place making and pedestrianscaled design, park-and-ride facilities are significant contributors to transit ridership. Merriam (1998) examined the relationship between park-and-ride space and train boarding for stations in the Chicago's METRA commuter rail system. The results indicate that each additional space increases ridership by between approximately 0.5 and 2.2 riders depending on other independent variables.

Acknowledging the positive correlation between station parking facilities and transit ridership, Duncan (2010), sought to determine the amount of density that would be needed 
to replace park-and-ride associated transit ridership with local TOD-associated ridership. Using the San Francisco Bay Area's BART system as a test case, Duncan found that more than one new unit or job would be required to replace the ridership associated with one park-and-ride spot. This would translate, in many cases, to densities over one-hundred units and/or jobs per acre, much higher than would typically be accepted outside of a central business district (CBD).

The literature indicates that while there are numerous challenges and costs that are associated with parking, parking tends to be an effective way of garnering ridership, something important to any transportation agency. Any changes to parking supply must consider these realities. As Tumlin and Millard-Ball (2003) note, even progressive and wellplanned TOD's tend to require large amounts of parking, whether in lots or in structures. The challenge then becomes how to reduce the impacts.

\subsection{Conclusion}

The TOD literature speaks strongly to the importance of place functions when planning for TOD. Consistently, emphasis is put on planning and designing at the human-scale, in terms of streets, block patterns, and distances between destinations. Scholars are in agreement on the importance of high (by North American standards) densities in order to create a critical mass of activity, and support the transit systems which lie at the heart of these urban environments. Parking is viewed in the literature as something of a double-edged sword, empirically recognized as contributing to ridership, but at the same time, identified as one of the elements preventing TOD from fulfilling its potential. 


\section{Chapter 3: Policy Review}

\subsection{Introduction}

This chapter will review the relevant policy from which flows the validation for a mobility hub planning exercise. The review will be used to target areas of importance, inform interventions, and make certain that any interventions do not run contrary to existing policy. The chapter will begin with provincial legislation, then examine the City of Toronto's Official Plan, and finally, review pertinent Metrolinx directives.

\subsection{Provincial Policy Statement, 2005}

The Provincial Policy Statement (PPS) sets the overall policy direction and tone on matters related to land use. Subsequent to section three of the Planning Act (R.S.O 1990), decisions on planning matters must be consistent with the PPS. The current PPS, adopted in 2005, puts a strong emphasis on the wise use of provincial resources. The PPS speaks directly to the need for urban intensification and development that is transit supportive.

The PPS includes a number of policies which have direct relevance to mobility hub planning. Consistent with what is reported in the relevant literature, this policy stresses that land use mix, densities, and development patterns can, and should be planned to minimize vehicle trips and encourage the viability of trips made by walking, cycling, and public transit. New development should provide a mix of housing, employment and other land uses. Addressing the creation or modification of streets, the PPS notes that streets should facilitate safe travel and not solely meet the needs of motorized vehicles, but pedestrians and non-motorized vehicles as well (PPS, 2005). 


\subsection{Growth Plan for the Greater Golden Horseshoe, 2006}

Enabled through the 2005 Places to Grow act, the Growth Plan for the Greater Golden Horseshoe (the Growth Plan) is intended to direct and manage the considerable growth expected in the GTHA through to 2031. The Growth Plan builds on the direction of the PPS and works towards the province's goals of urban intensification and agricultural preservation. This is achieved namely by the identification of urban growth centres and prescribed intensification targets. The Kennedy Mobility Hub is not identified as an urban growth centre, however, nearby Scarborough City Centre is. The growth plan also mandates that by the year 2015 , all municipalities must ensure that $40 \%$ of residential growth occurs in already "built-up areas."

Of particular importance to mobility hub planning are the policies for major transit stations under section two. Major transit stations areas are defined as being within a 10-minute walk of a higher-order transit station. This translates to a roughly the 800 meter threshold within which people are willing to walk to higher-order transit, consistent with what has been put forth by scholars (Ewing and Bartholomew, 2013; Griffin, 2004; Morris, 1996). These areas are to be identified in municipal official plans, employment and residential densities are to be increased, and they should be planned for a broad mix of land uses wherever possible. Transportation policies under section three include provisions stating that transportation and land use planning must be coordinated. Furthermore, municipalities must ensure that bicycle and pedestrian networks are integrated in transportation plans.

\subsection{City of Toronto Official Plan, 2010}

The City's Official Plan (OP) sets out the present policy and direction on matters of land use, and to a lesser extent, economic and social policies. Subsequent to the Planning Act, the OP must be consistent with the PPS and conform to all provincial plans. Though the OP does not restrict land use in-and-of itself, zoning by-laws, which do restrict land use, must 
conform to the OP. Furthermore, public works cannot be undertaken unless they conform to the OP. The OP designates lands within the city for different purposes. There are a number of land use designations which applying to Kennedy Mobility hub or the surrounding area that need to be considered.

This section of Eglinton Ave., and all of the land adjacent to the Station, is designated in Toronto's OP as "mixed use." This mixed use designation is significant since it allows for the incorporation of a range of residential and commercial uses. This also holds significance in the context of the forthcoming Crosstown LRT since mixed use designations, which hold the potential to provide significant residential and employment-based ridership, are limited along the planned Crosstown route.

Eglinton Avenue, onto which Kennedy Station fronts, is also designated as an "Avenue" in Toronto's OP. Importance is placed on Avenues in the OP as areas to accommodate future residential, retail, and office intensification. The OP states that a detailed Avenue Study is to be completed for each designated avenue. An Avenue Study for Eglinton Ave. is currently underway and is scheduled to be completed in early 2014 . Once completed, this study will provide recommendations for the Kennedy Mobility Hub. In the meantime, the OP sets provisions for avenues not currently covered by a study. Mixed use areas along avenues must be supportive of transit, contribute to a range of housing options, contribute to a safe and comfortable walking environment which supports local retailing. More generally, mixed use areas must provide a sensitive transition to surrounding 'neighbourhoods,' which are to be treated as stable areas.

In respect to new development, the OP states that, where appropriate, large sites will be divided into smaller blocks and new streets will connect to adjacent neighbourhoods, design considerations which the literature shows to be supportive of walkability and transit (Cervero and Ewing, 2010). New sidewalks will be designed to provide safe, attractive and interesting 
space by providing well-designed landscaping and street trees, lighting, and quality street furnishings. New developments should generally be located parallel to the street and give prominence to corner locations. Parking between the front face of a building and the public realm is to be limited.

The OP also includes provisions for securing new parkland through parkland dedication. New residential development must dedicate $5 \%$ of its area for parkland while all other uses must dedicate $2 \%$. New parks and open spaces should, wherever possible, be located to extend existing parks and natural areas. Parks should also front onto street where possible, providing visibility, access and safety.

\subsection{The Big Move Regional Transportation Plan, 2008}

Released in 2008 by Metrolinx, the GTHA's regional transit authority, the Regional Transportation Plan (RTP) presents a plan for the overhaul and expansion of the region's tired transit infrastructure. While the RTP is not binding legislation, the policies and programs therein seek to carry out the policies of the PPS and Growth Plan. The plan is organized into a series of "Big Moves," the seventh of which is the establishment of a system of mobility hubs.

The plan identifies 51 mobility hubs throughout the region. These station areas have been selected because of the high level of service that they provide and the development potential surrounding them. These hubs have the potential to become vibrant places of activity and destinations in and of themselves.

The plan also states that each municipality, in consultation with relevant transit agencies, must set out a detailed master plan for each mobility hub. These should, among other things, set minimum density targets, establish surface parking reduction strategies and identify and optimize transit-oriented development potential. Additionally, the plan emphasizes that stations must be planned to maximize integration of transit services, 
maximize ridership, maximize integration with surrounding neighbourhoods, and prioritize access by transit, cycling and walking.

\subsection{The Mobility Hub Guidelines, 2011}

The Mobility Hub Guidelines (the Guidelines) were unveiled by Metrolinx in 2011. The Guidelines are intended to help communicate the mobility hub concept and its objectives, as well provide guidance in their development. While the guidelines do not represent legislated policy, they do act towards carrying out the goals of the RTP as well as broader provincial policy.

Recognizing that not all mobility hubs are the same, the Guidelines classify the region's 51 designated mobility hubs according to their role and location within the region. Kennedy is identified as a Gateway mobility hub. Gateway hubs are expected to see significant activity and are to achieve minimum densities of 50 people and jobs combined per hectare. Contrasted against the relevant literature, this represents a fairly modest target, just shy of what most scholars consider to be transit supportive (Calthorpe, 1993; Griffin, 2004; Cervero and Guerra, 2011).

When planning for parking, the Guidelines recommend that commuter parking needs be assessed on a system-wide basis as opposed to the individual site basis. Parking should also be planned so as to maximize development potential within mobility hubs. Additionally, parking needs are encouraged to be met by integrating parking with surrounding developments where possible.

\subsection{Conclusion}

Towards realizing goals of efficient and transit-supportive forms of development, planning for mobility hubs is encouraged directly by the RTP and indirectly by the Growth Plan, which encourages that transit and land use planning be coordinated. At all levels, policy 
encourages pedestrian and bicycle supportive mixed use development around transit stations. This policy direction echoes, to a large degree, the spirit and recommendations of the TOD literature.

While there is an established history of planning for transit-supportive nodes in the GTHA (Filion, 2006), the current policy direction's level of focus on transit-supportiveness represents a significant step in this planning paradigm. Metrolinx's RTP and the Guidelines are some of the most recent and clearest developments in this evolution.

Metrolinx's 51 designated mobility hubs range widely in their urban nature and ability to become transit-supportive. Some of the mobility hub locations least conducive to transitand pedestrian-supportiveness are suburban Gateway hubs. While there may be some national or international case studies to draw upon, there is little local precedence for the full-scale transformation of suburban transit nodes into the kinds of mobility hubs envisioned by Metrolinx. What will the policies, recommendations, and guidelines reviewed in the last two chapters look like when applied on the ground? What might the results be and what pragmatic challenges will be faced? 


\section{Chapter 4: Kennedy Mobility Hub Context}

\subsection{Introduction}

A thorough understanding of the site and its surrounding context is necessary in order to arrive at sound and informed goals and subsequent interventions. This chapter will briefly discuss the Station's present and future transit functions, the area's historical context, as well as its built and human characteristics. The review is based upon observations made during a number of site visits (see Appendix 1) as well as secondary research.

\subsection{Present Role in Toronto's Transportation System}

Kennedy Station is located in Toronto's east end within the pre-amalgamation City of Scarborough. The Station is situated on the south side of Eglinton Avenue, just east of Kennedy Road. Figure 4.1 illustrates the situation of Kennedy Station and some of the surrounding features that will be referred to throughout this project.

Kennedy Station is the eastern terminus for the Bloor-Danforth subway line and the western terminus for the Scarborough Rapid Transit (RT) line (see Figure 4.2). The Station's primary function is as an access and transfer point between these two busy systems. The Station is also serviced by GO Transit's Stouffville rail line and 11 local TTC bus routes (TTC, 2013). On an average weekday, the Station serves as an access, exit, or transfer point for over 100,000 transit riders, making this the fourth most trafficked station in the TTC system (TTC, 2010). 
Figure 4.1 Kennedy Station and Surrounding Context

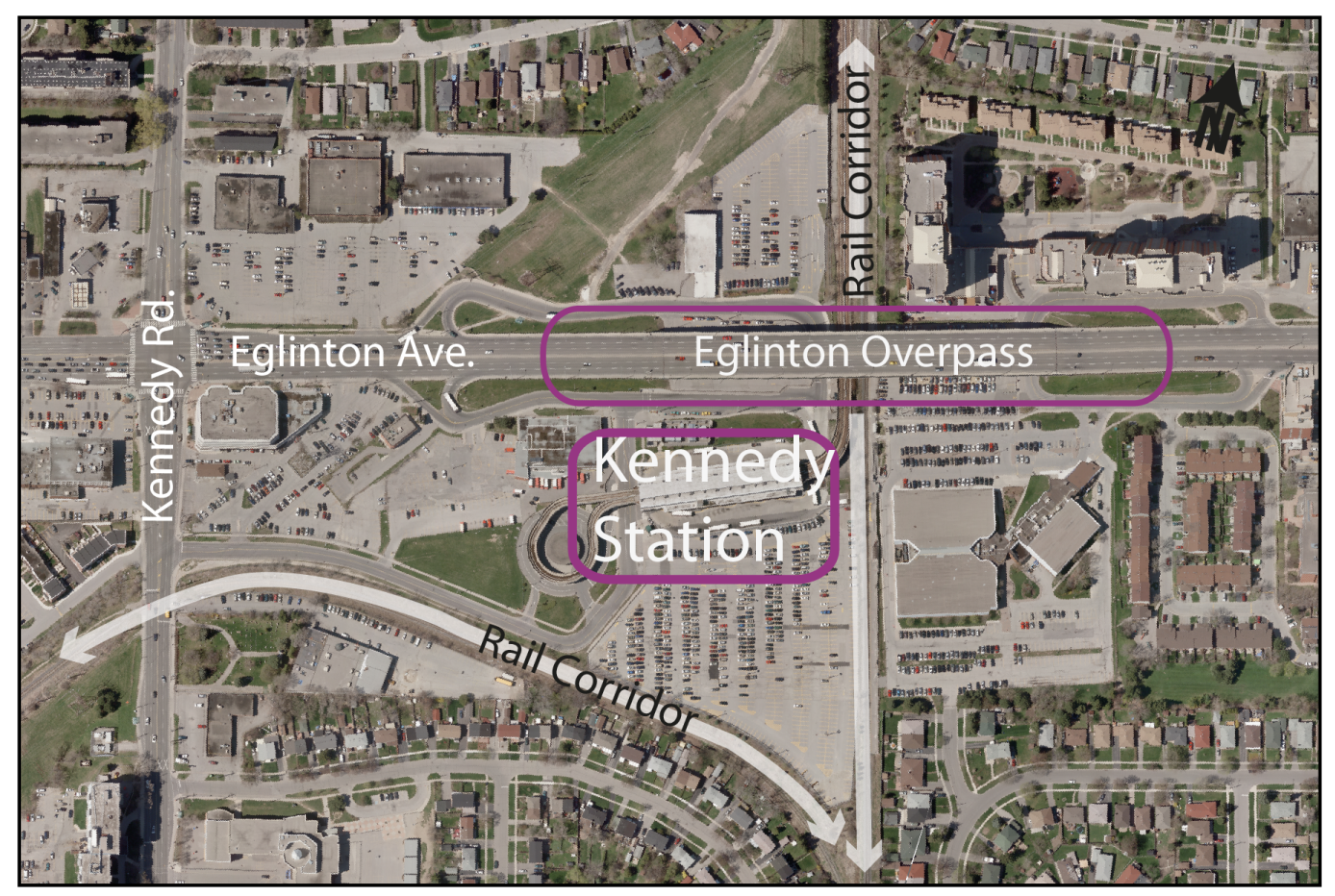

Image Courtesy University of Toronto, annotations by author

Figure 4.2 Kennedy Station Transit Context

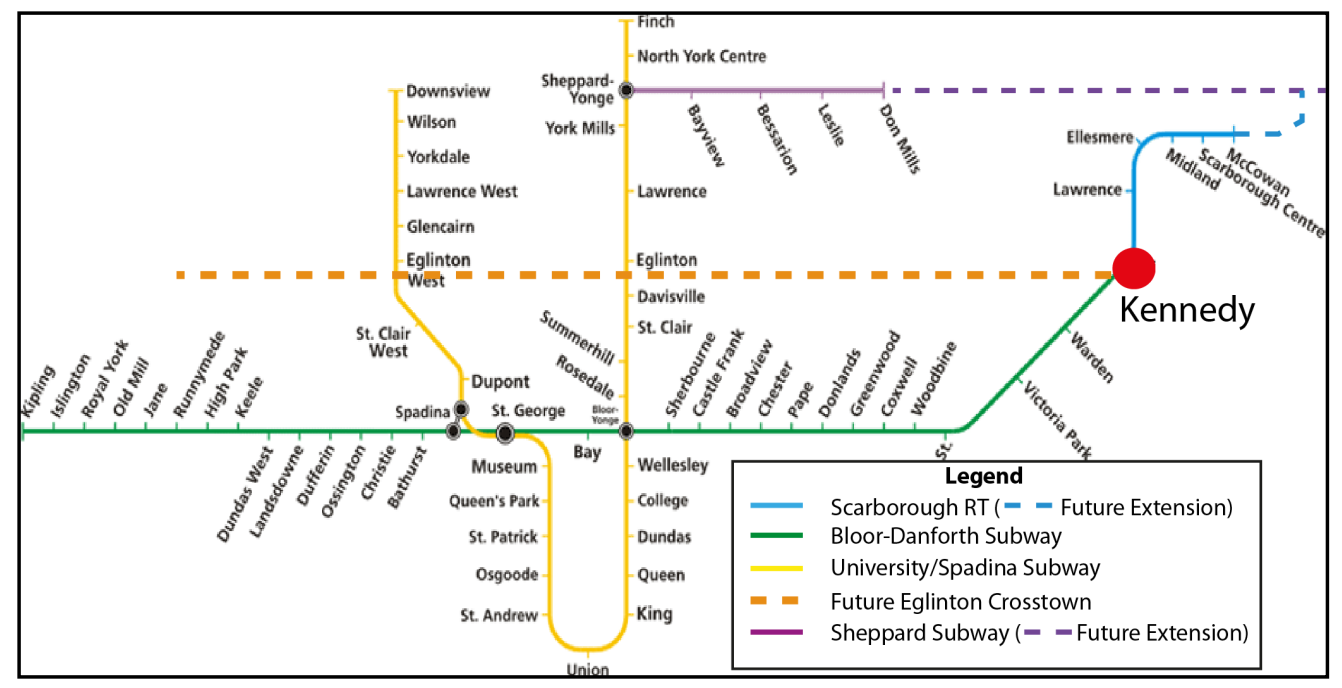

Image courtesy TTC, annotations by Author 


\subsection{Future Role in Toronto's Transportation System}

Kennedy Station's significance as a transit node will increase in the future following the arrival of the Eglinton-Scarborough Crosstown LRT line, now under construction and slated for completion in 2020 (Metrolinx, 2013). Much of the technical and logistical plans for this project are outlined in the Eglinton Crosstown Project Assessment Study (2010). The

Scarborough RT, meanwhile, is set to undergo expansion and train replacement, also slated for completion by 2020 (Metrolinx, 2013). As part of that project, the SRT's connection to the Station is planned to be re-located from its current elevated point-of-entry to an underground point-of-entry. As part of Toronto's former Transit City plan, Kennedy was to be the western terminus for the Malvern LRT, however, that project is currently not active (TTC, 2010).

Bus service will continue to be an important part of the Station's transit functionality in the future. The higher-order transit improvements mentioned above can be expected to, in turn, increase demand for 'feeder' bus service to-and-from the Station.

\subsection{Historical Context}

Kennedy Station opened in 1980 to accommodate the final eastward expansion of the Bloor-Danforth Subway line. The Scarborough RT platform became operational five years later, in 1985, with the completion of that line (TTC, 2013). The Scarborough RT currently uses driverless 1970's era trains, though interestingly, it was initially planned to use the same CLRV 'streetcars' that are in use on many of Toronto's city streets today. The elevated turn-around loop, a prominent station feature, was found to be incompatible with the RT trains and is not used but remains today (Filey, 1996). Kennedy's GO train platform was added in 2005 to accommodate this added stop on the pre-existing Stouffville line (Transit Toronto, 2006). Much of the existing development surrounding Kennedy Station pre-dates the Station itself, as can be seen in Figure 4.3. Much of the residential and 
commercial development in the area appears to be constructed between the post-World War II to mid-1970's era. There are, however, some notable exception such as the more recent 17-storey towers of the Rainbow Village Condo Complex, seen in the bottom lefthand corner of Figure 4.4.

Figure 4.3 Kennedy Stn. Area Before Station Construction, Looking W. Along Eglinton Ave.

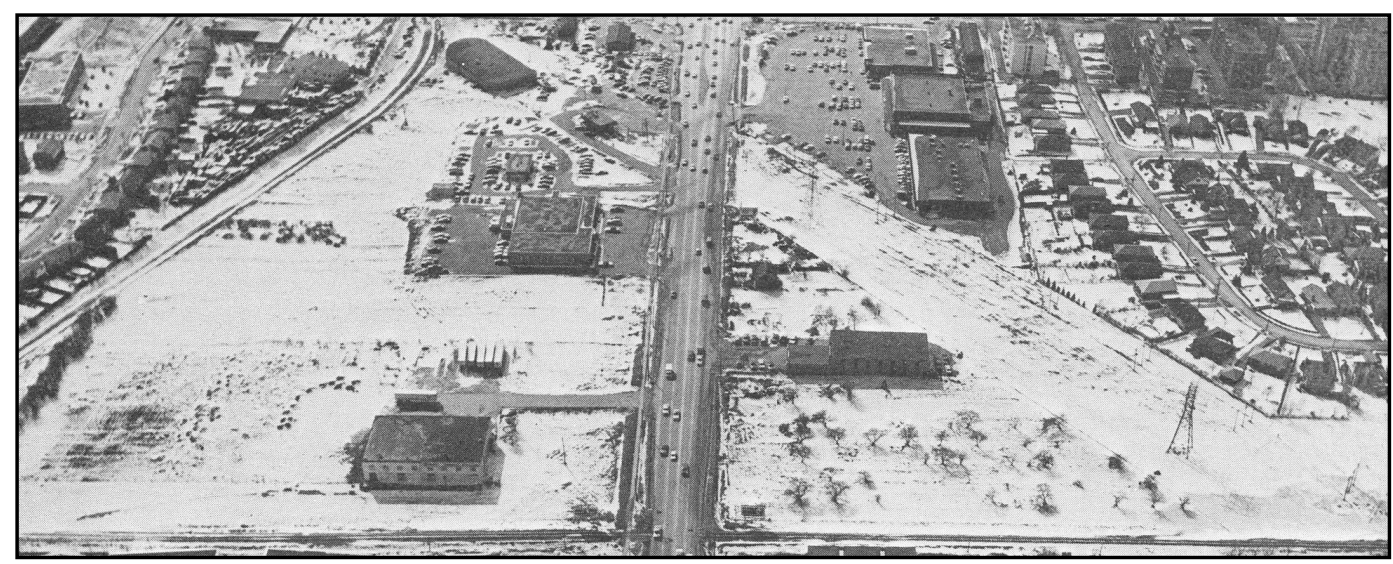

Image Courtesy TTC

Figure 4.4 Kennedy Station Area as it is Today, Looking West

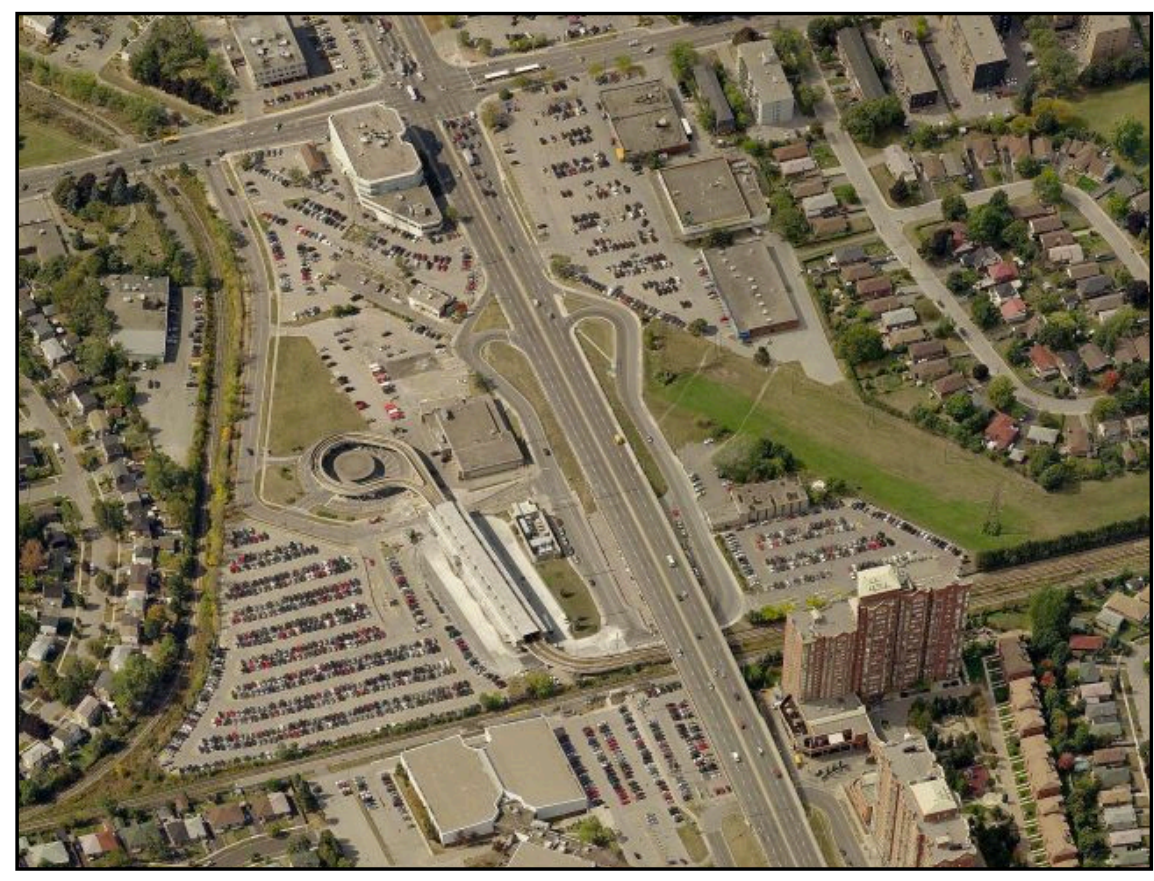

Courtesy Bing Maps 


\subsection{Site Function}

Figure 4.5 illustrates Kennedy Station's current above-ground transportation functionality. While the Bloor-Danforth subway enters the Station beneath the building's surface, the Scarborough RT enters the Station above ground on a raised platform. The GO train platform lies directly east of the Station and is connected to the main Station through an underground walkway. Surrounding the station building at ground level is the bus platform area. A taxi pickup area is located on the north side of the Station in-between the station building and Eglinton Ave. A kiss-and-ride (passenger pick-up and drop-off) area is located to the west of the station building.

A number of site features constrain pedestrian access to the Station. The most notable of these are the Eglinton Ave. overpass; the east side rail corridor; the south side rail corridor; and the bus platform area. Each of the four foot-access points is set away from the Station, taking pedestrians below ground-level to circumvent site barriers.

Figure 4.5: Kennedy Station Current Transit Functionality

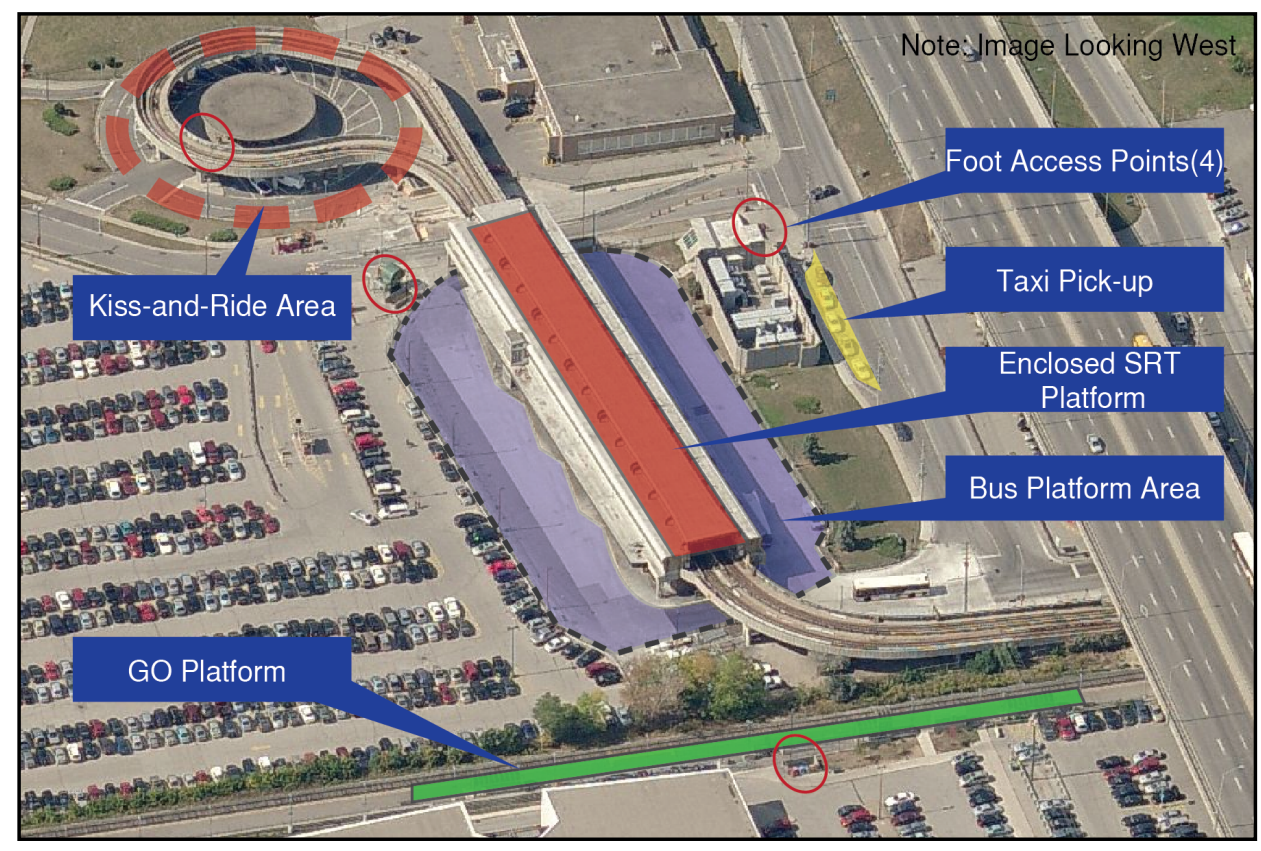

Courtesy Bing Maps, annotations by Author 


\subsection{Surrounding Context and Characteristics}

\subsubsection{Parking}

The mobility hub area is currently characterized by an abundance of surface parking lots.

Figure 4.6 shows each of the four TTC owned parking lots. In total, these lots make up approximately 29,000 square meters of gross surface parking area or 1,200 spaces, based on aerial and site-visit counts. A large City-owned parking lot to the east of the Station surrounds the Don Montgomery Community Recreation Centre and is also utilized by commuters as well as visitors to the Centre.

Figure 4.6 TTC Operated Parking at Kennedy Station

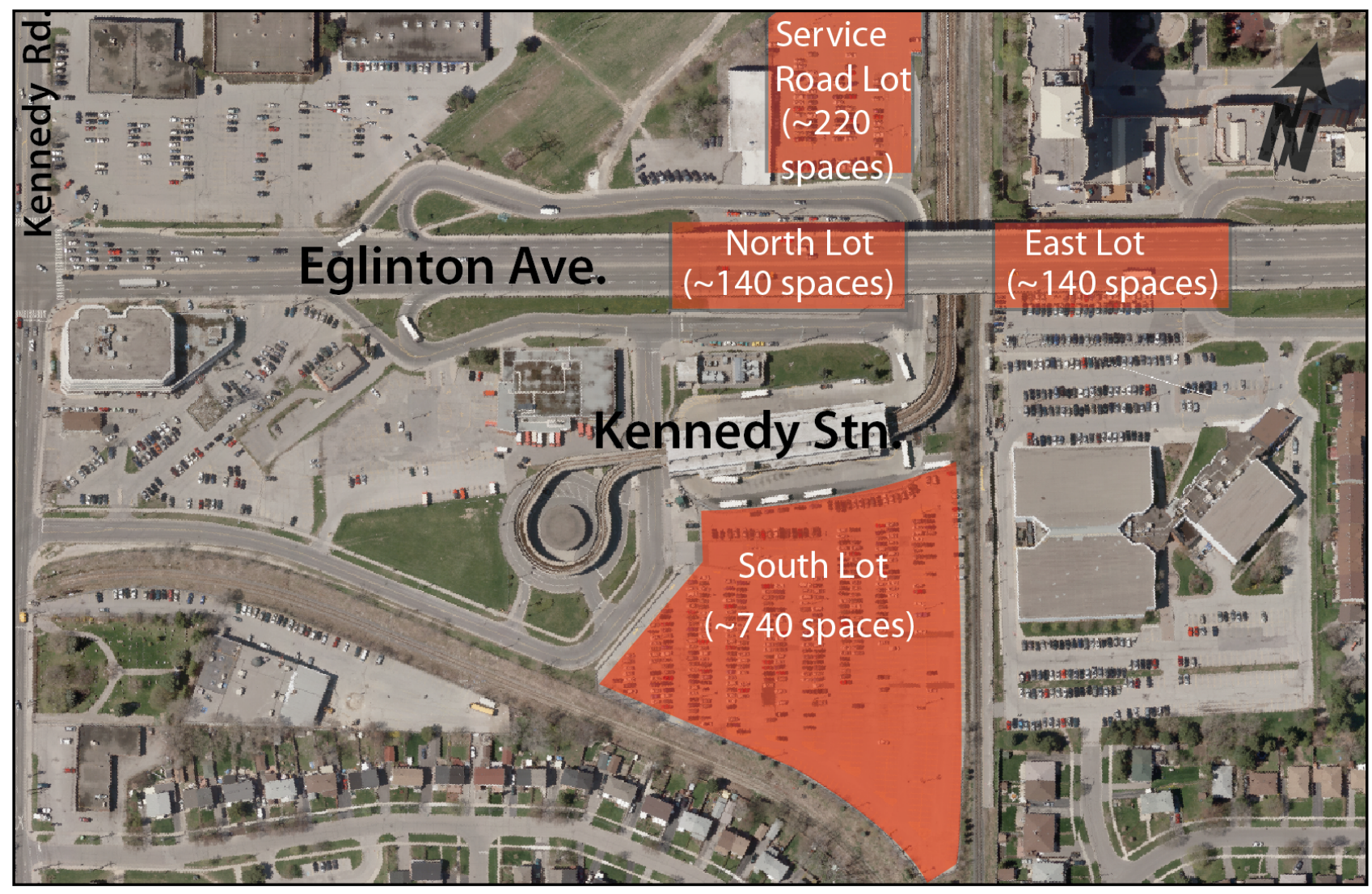

Courtesy University of Toronto, annotations by Author 


\subsubsection{Built Form}

The area's built form is characterized by low-rise commercial buildings and mid- to high-rise residential buildings. Strip plazas with generous setbacks dominate the landscape along Eglinton Ave. There are, however, several exceptions like a mid-rise office and retail building on the south-east corner of Kennedy Rd. and Eglinton Ave. Beyond Eglinton Ave., stable neighbourhoods and apartment neighbourhoods predominate. The majority of neighbourhood dwellings are post-war style suburban bungalows of the type found across Scarborough and throughout the GTA.

\subsubsection{Gatineau Hydro Corridor}

The central Station area is transected by a segment of the Gatineau Hydro Corridor, as illustrated in Figure 4.7. The corridor runs in a north-south direction and is grass covered on the north side of Eglinton Ave. where it hosts a recreational trail. To the south of Eglinton Ave., the hydro corridor area serves as surface parking.

Figure 4.7 Gatineau Hydro Corridor and Recreational Trail

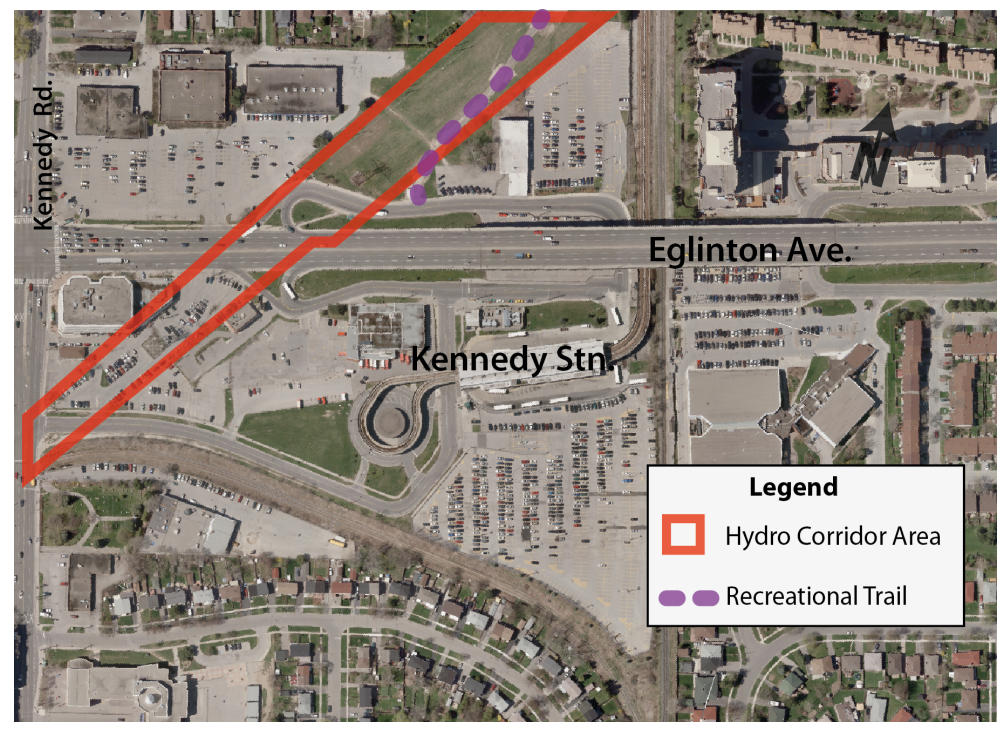

Courtesy University of Toronto, annotations by Author 


\subsubsection{Eglinton Avenue Bridge}

Eglinton Avenue is the area's main traffic and commercial artery. This six-lane road is elevated by an overpass (bridge), as annotated in Figure 4.1. The bridge begins its ascent almost directly in-front of the station building and carries the road over the GO transit/CN and Scarborough RT tracks that lie directly east of the station building. Ring-shaped service roads on both the east and west sides of the overpass run underneath, parallel to, and then join Eglinton Ave., where it begins its ascent. The western ring-road allows busses and cars easy access to the Station.

\subsubsection{Land use}

To assess the land use mix within the Kennedy Station area, an inventory of land uses was undertaken and is illustrated in Figure 4.8. An 800 meter radius buffer around the Station was chosen as the inventory boundary to coincide with the $800 \mathrm{~m}$ radius used by Metrolinx in mobility hub definition.

Non-residential uses, predominantly retail, service, and food service, are clustered along Eglinton Ave., however, most of these are at least 150 meters from the station building.

\subsubsection{Parkland and Public Open-Space}

While there are a number of small neighbourhood parks woven throughout the residential areas of the mobility hub, one noteworthy open-space feature is the Gatineau Recreational Trail within the Gatineau Hydro Corridor, seen in Figures 4.9 and 4.10. The trail ends at Eglinton Ave. across from Kennedy Station, as seen in (Figure 4.9), but resumes (informally) along the railroad corridor to the south-west of the Station. 
Figure 4.8: Land Uses Surrounding Kennedy Station

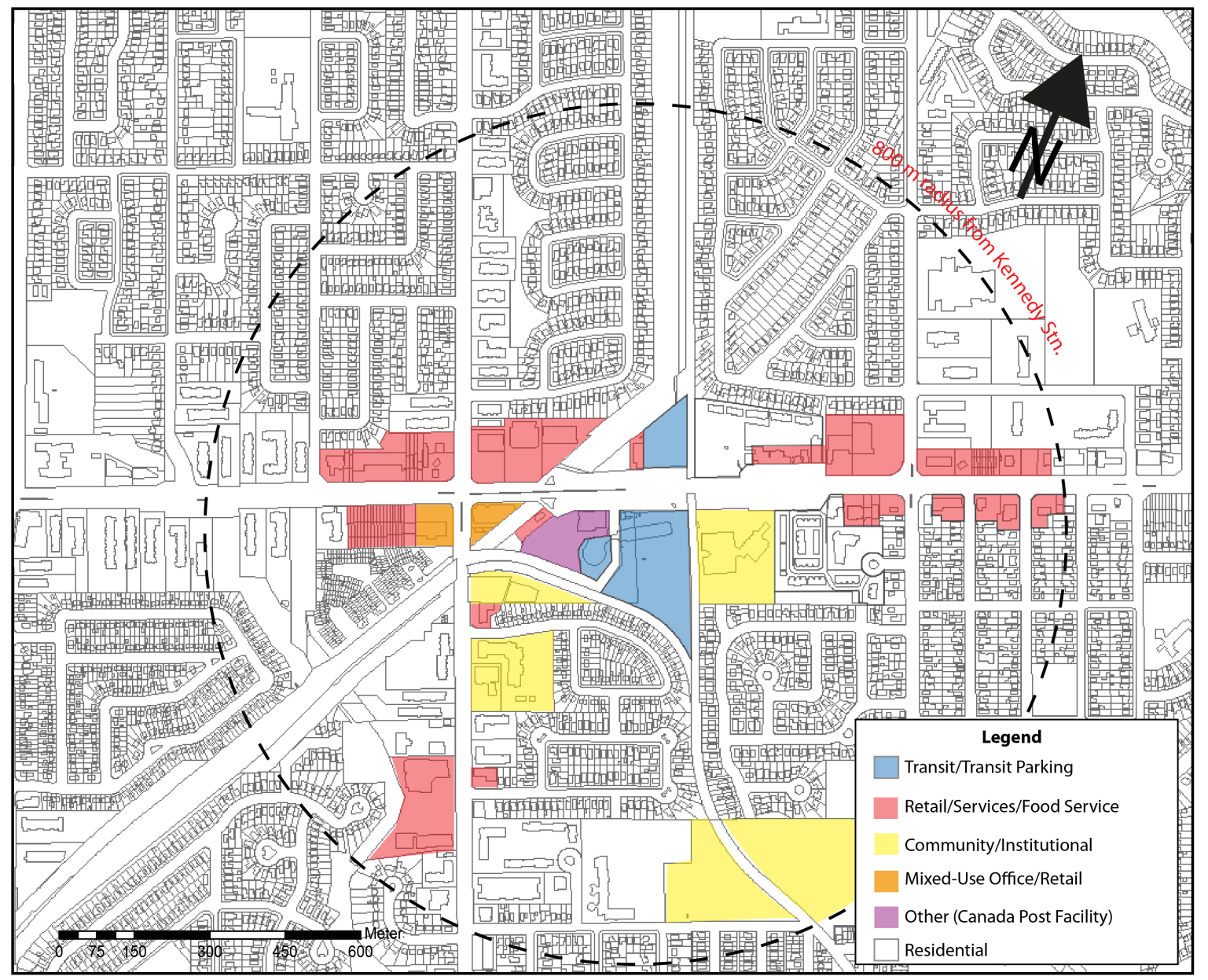

Courtesy Ryerson University, annotations by Author

Figure 4.9 and 4.10: Gatineau Recreational Trail
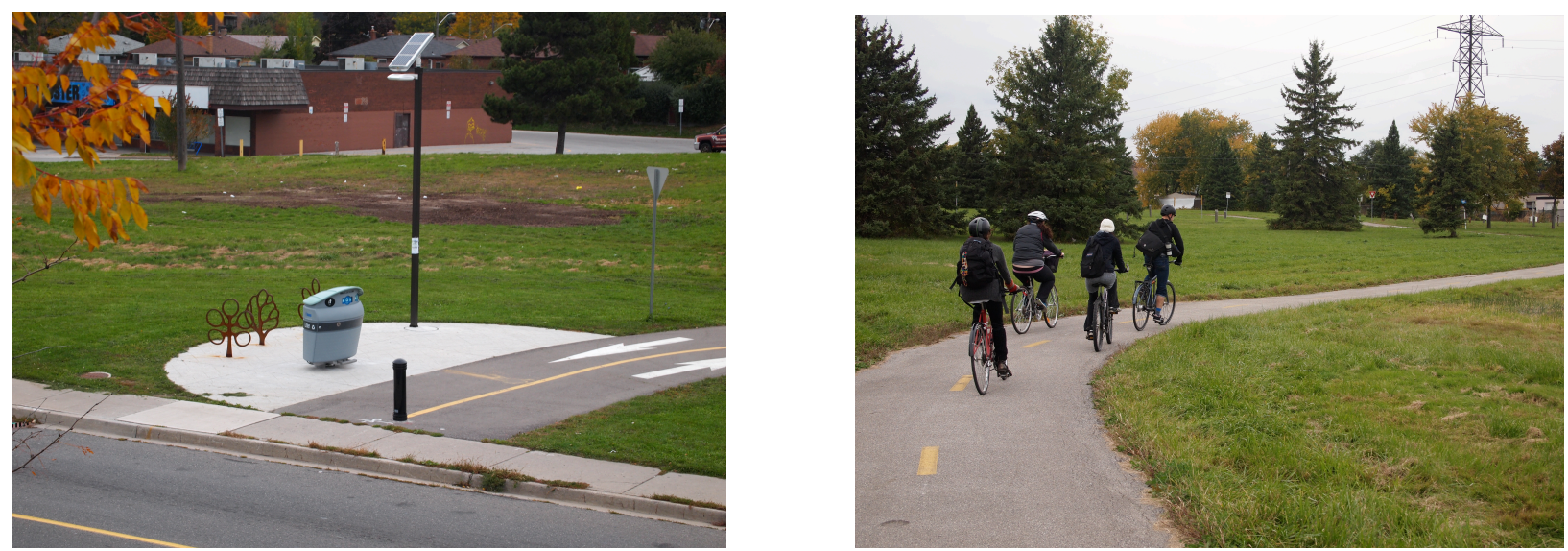


\subsection{Local Demographics}

Approximately 14,000 people live within Kennedy Station's 800 meter mobility hub catchment area. A significant proportion of these inhabitants (76\%) are young immigrants, the majority of whom are of South Asia, Middle-Eastern, and Latin America origin (Metrolinx, 2012). With an average household size of 2.8 people, there are approximately 5000 households in the catchment area. Approximately $59 \%$ of households live in apartment or condominium buildings ( 5 storeys or higher), $21 \%$ live in single-detached dwellings, while the remaining $20 \%$ live in other dwelling types (Metrolinx, 2012).

\subsection{Residential and Employment Density}

According to data released by Metrolinx (2012), the area within an 800 meter radius of Kennedy Station contains approximately 14,000 inhabitants and 1,000 jobs. This translates to a residential density of 7 people per hectare and 0.5 jobs per hectare, or a combined people and jobs density of 7.5 per hectare. This density is far below the minimums typically recognized to be needed in order to support higher-order transit investments. As discussed in Chapter Two, minimum densities of around 60 residents/hectare are typically recommended by scholars (Calthorpe, 1993; Griffin, 2004; Daisa, 2003).

\subsection{Context Review Conclusion}

A review of Kennedy Mobility Hub's local context reveals a number of challenges and opportunities from a mobility hub planning perspective. Local assets include the community recreation centre, the recreational trail, as well as nearby retail commercial land uses. Commercial land uses are shown to be transit supportive (Loo et al., 2010), however, the distance of these amenities from the Station diminishes their convenience to transit riders. Distances are made even greater on the ground by site barriers such as the hydro corridor, overpass, rail corridors, and large expanses of surface parking. Additionally, low residential density, and even lower employment density are un-conducive to an animated urban 
environment. Interventions at Kennedy must focus on creative ways to overcome site barriers, incorporate a greater mix of land uses, and increase density. 


\section{Chapter 5: Concept Plan Project Parameters}

After reviewing the relevant literature, policy, and the existing context, interventions can now be considered for Kennedy Mobility Hub. This chapter will establish the project boundaries, assumptions, and goals that inform the direction and limitations of the concept plan introduced in the Chapter Six.

\subsection{Defining the Mobility Hub Study Area}

In order to establish study boundaries, this project delineates a mobility hub primary zone, secondary zone, and tertiary zone, as illustrated in Figure 5.1. While this project's direct proposals for land use interventions will be limited to the primary zone only, reference will be made to the secondary and tertiary zones. The delineation of these boundaries was undertaken with direction from the Mobility Hub Guidelines.

The primary zone is focused within roughly 250 meters, or 2.5 minutes' walk of Kennedy Station, as per the Guidelines. This zone is delineated to include all of the TTC owned parking lands as well as the City-owned Don Montgomery Recreational Centre lands. As publicly held real estate, these parcels present the greatest opportunities for change. Also included are the Canada Post-owned lands directly to the west of the Station; segments of the Gatineau Hydro Corridor; and the commercial lands directly north-west of Kennedy Station.

The Seconday zone is split into two segments. The eastern segment runs from the primary zone boundary, along Eglinton Ave., until lonview Rd. where stable apartment neighbourhoods, designated in the City's OP, begin. The secondary zone, like the primary zone, has been delineated to exclude neighbourhoods and apartment neighbourhoods, for which little change is to be expected. Part of the justification for stretching the eastern 
secondary zone a full 800 meters along Eglinton Ave. is the short block lengths along the south side of the street, which have the potential for pedestrian-encouraging travel to-andfrom the Station.

Figure 5.1: Project Primary, Secondary, and Tertiary Zones

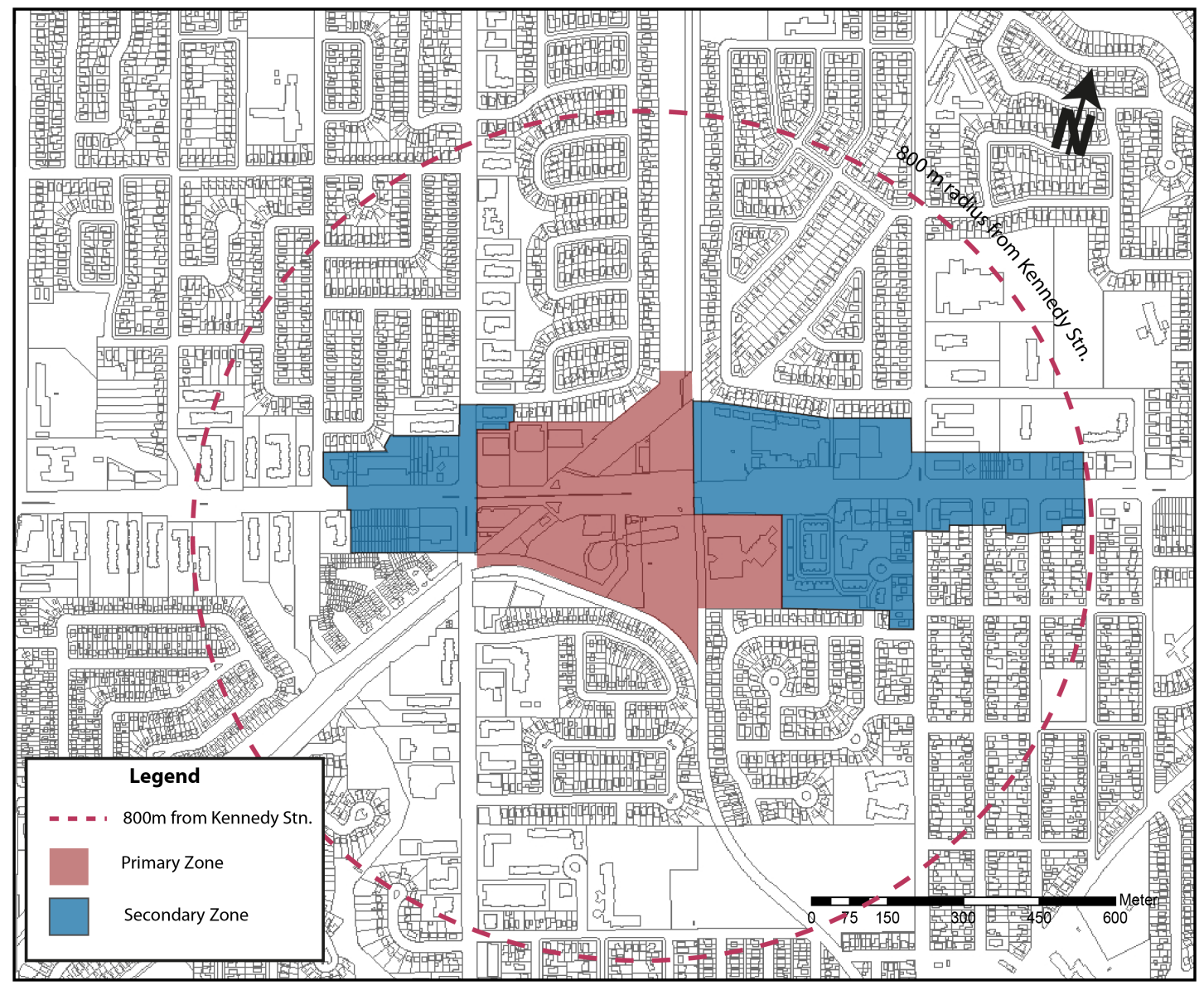

Courtesy Ryerson University, annotations by Author

\subsection{Project Assumptions}

The project works from the assumption that the Station area, and public landholding in particular, will undergo significant re-development as part of the Crosstown LRT project and 
Scarborough RT renewal. It should also be noted that, as a conceptual planning project, costing and financial considerations are beyond the project's scope.

Far from being a blank slate, this site is constrained by many barriers and limitations presented by existing and planned infrastructure. The site plan works from a number of fixed site assumptions, the first of which is the placement of underground transit connections as illustrated in Figure 5.2. It is assumed that underground transit connections cannot be built upon, with the exception of the station building. It is also assumed Gatineau Hydro Corridor cannot be moved and that buildings cannot be constructed within it.

Figure 5.2: Underground Transit Connections Present and Planned

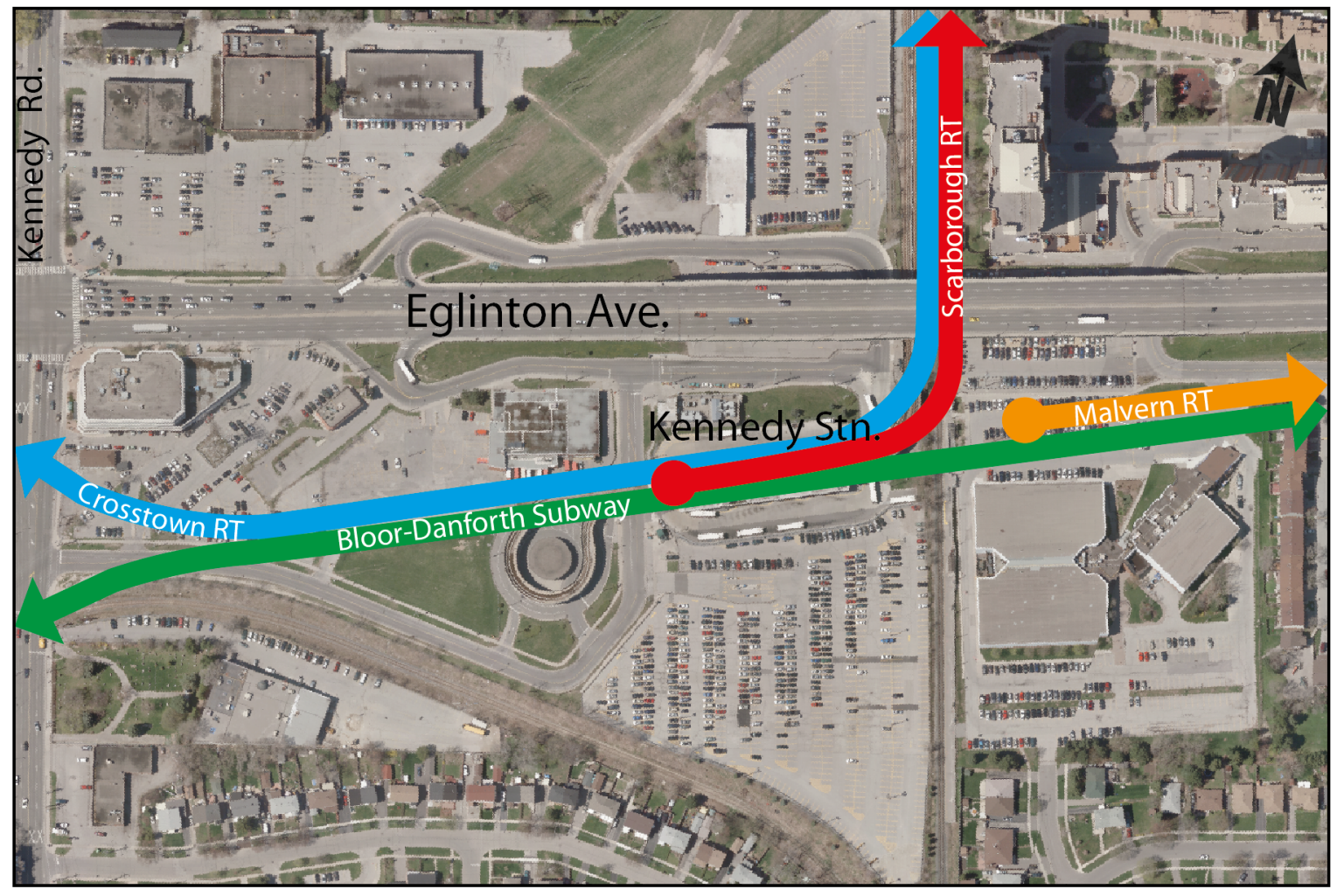

Courtesy University of Toronto, annotations by Author 


\subsection{Project Goals}

The mobility hub concept plan attempts to address a set of six goals which are based on conclusions drawn from the pertinent literature, policy, and context review. Though certainly not an exhaustive list of what mobility hub planning should strive to achieve, the goals focus on outcomes that are critical elements in mobility hub planning, and are within the realm of urban planning. The six goals, as well as a brief description of their respective rationale, follows.

Goal 1: Increase residential and employment density to at least 60 people and jobs combined per hectare, while proposing a built form that is sensitive to surrounding neighbourhoods.

Transit supportive densities are critical to establishing the ridership needed to justify higherorder transit investments (Cervero, 1997; Cervero and Guerra, 2011; TCRP, 2004), as well as facilitating the creation of a vibrant urban environment (Metrolinx, 2011; Belzer and Autler, 2002; TCRP, 2004; Ewing and Bartholomew, 2013). The current density at Kennedy Mobility Hub is 7.5 people and jobs per hectare. In contrast, the Guidelines suggests a minimum density of 50 people and jobs per hectare and scholars recommend minimums of around 60. Considering the extent of developable mixed use lands and environmental and infrastructural buffers separating potential development areas from stable neighbourhoods, 60 people and jobs per hectare should be achievable.

\section{Goal 2: Achieve a more complete mix of transit-supportive land uses.}

A diverse mix of land uses contributes to varied transit ridership patterns and contributes to the convenience of transit by facilitating trip-chaining (Cervero, 2006; Belzer and Autler, 
2002). Employment land uses, aside from retail, are few in the mobility hub and retail uses are under-represented at the centre of the mobility hub where they are most critical to the convenience of ridership. Adding additional employment uses to the primary zone and commercial retail uses in close proximity to the Station will strengthen the Hub's 'location efficiency.'

\section{Goal 3: Create a parking strategy which replaces all surface parking currently on developable public lands.}

Park-and-ride facilities (in the North American context) have been empirically shown to be positively correlated with transit ridership (Merriam, 1998). Surface parking at Kennedy, however, is not conducive to pedestrian-supportive design or horizontal scale. Surface parking is also currently located on land that could otherwise be developed towards density, land use diversity, and place-making goals. To balance both the node and place goals of TOD, the concept plan will seek to replace parking in a way that does not diminish the human environment.

\section{Goal 4. Improve the travel experience and accessibility for pedestrians and cyclists.}

Through pedestrian conducive design and by shortening walking distances to destinations, people can be persuaded to choose walking and transit over cars (Ewing and Bartholomew, 2013; Belzer and Autler, 2002; TCRP, 2004). This is also supported strongly by planning policy at all levels. Likewise, incorporating bicycle lanes and other bicycle supportive design features into mobility hub design will also work towards this goal by effectively expanding 
the transportation catchment area, and mitigating demands for surface parking (Pucher, 2009).

\section{Goal 5: Identify opportunities to improve and expand parkland and greenspace.}

The need to provide sufficient parkland in the context of new development is made clear in Toronto's OP. The Guidelines also encourage, where possible, the expansion and integration of existing greenspace networks into mobility hub re-development plans. Ultimately, these policies work towards achieving near-universal ideas of "livability", as Belzer and Autler (2002) note.

\section{Goal 6: Ensure seamless mobility while meeting all goals.}

While the previous five goals work towards the place functions of TOD, these can often be at odds with the transportation, or node functions of TOD (Filion, 2006; Belzer and Autler, 2002; Bertolini, 1998). Ensuring Seamless mobility is the first of The Guidelines' seven goals. Compromising transit functionality by giving total priority to place-making goals could have the effect of undermining the purpose of TOD. All decisions made towards achieving goals 1-5 set out above will be considered against potential effects on the Hub's transportation functions. 


\section{Chapter 6: Concept Plan for Kennedy Mobility Hub}

\subsection{Introduction}

This chapter will present the mobility hub concept plan, which is the central product of this project. This concept plan takes a high-level perspective focused on the broad functions and uses of the mobility hub primary zone. This plan does not include fine-scale design elements such as street furniture or lighting, nor does it specify precise dimensions for site attributes.

Figures 6.1 and 6.2 contrast the extensive change envisioned in the concept plan, intended to represent a full-scale transformation from inner-suburban commuter node to urban mobility hub. The concept plan's foundational elements include a number of newly introduced or re-aligned roads, which create a permeable urban fabric and allow for streetfronting development. A re-imagined Kennedy station building is linked directly to the Eglinton Bridge, and a green corridor running through the mobility hub provides parkland and an integrated extension of the Gatineau Trail. This chapter will discuss the concept plan's site functionality and features in detail, explaining the associated rationale and how these differ from what exists currently.

Figure 6.1: Kennedy Mobility Hub Existing

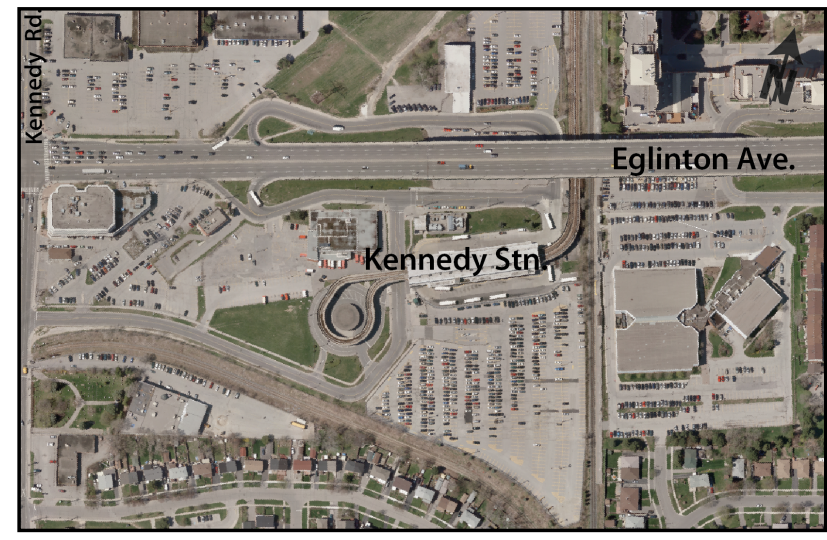

Figure 6.2: Kennedy Mobility Hub Envisioned

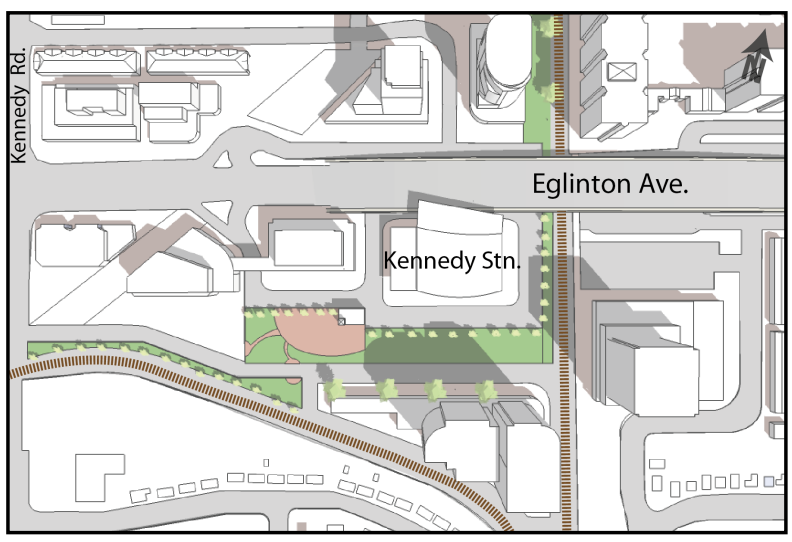

Courtesy University of Toronto 


\subsection{Site Functionality: Street Network}

The concept plan proposes a number of adjustments to the street pattern in the primary zone which are illustrated in Figure 6.3. While these are necessary, in part, to provide vehicular access to new development areas and other site features, they are equally valuable for their contribution to walkability. A finer-grained urban environment can contribute to reduced walking distances, a critical aspect of mode choice decision (Cervero and Ewing, 2010; Ewing and Bartholomew, 2013). Retrofitting the existing street network within mobility hubs is also a strategy recommended by the Guidelines towards achieving a more walkable, human-scaled environment.

Figure 6.3 Envisioned Changes to Road Network, Kiss-and-Ride, and Taxi Area

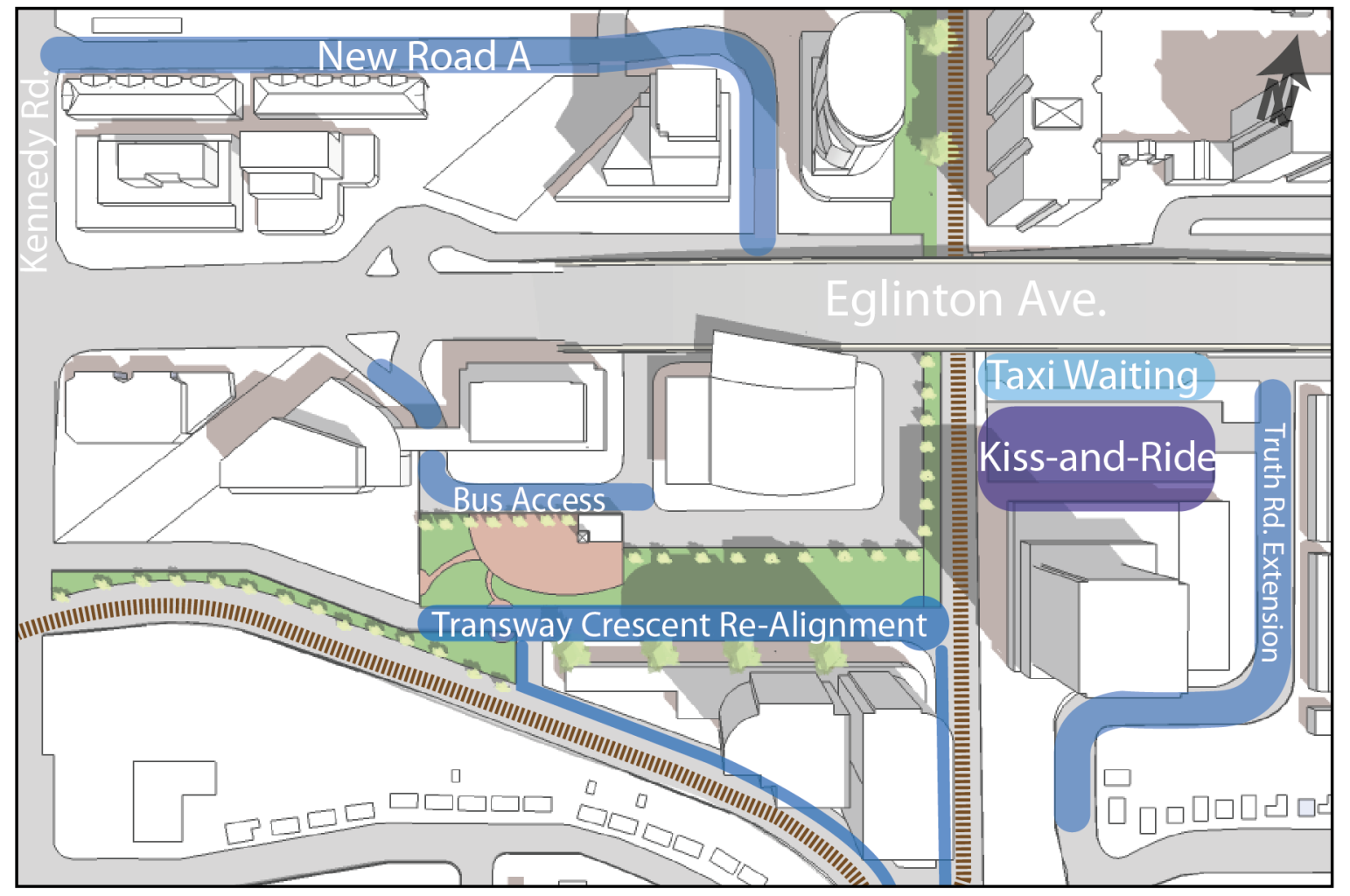

The most significant modification to the street network in the primary zone is New Road A. This road provides access from Kennedy Rd. to the envisioned development sites north of 
Kennedy Station and envisioned hydro corridor surface parking (discussed later), linking finally to the North Service Road. Here an envisioned underground walkway will connect transit users to the station building. The creation of this road would require land to be acquired from three commercial property owners, as well an agreement with Hydro One, the corridor owner.

While the creation of New Road A is the preferred option, an alternative and less logistically challenging option is illustrated in Figure 6.4. This alternative option would provide access to development sites and hydro corridor parking but adds little to the area's permeability.

\subsection{Alternative to New Road A}

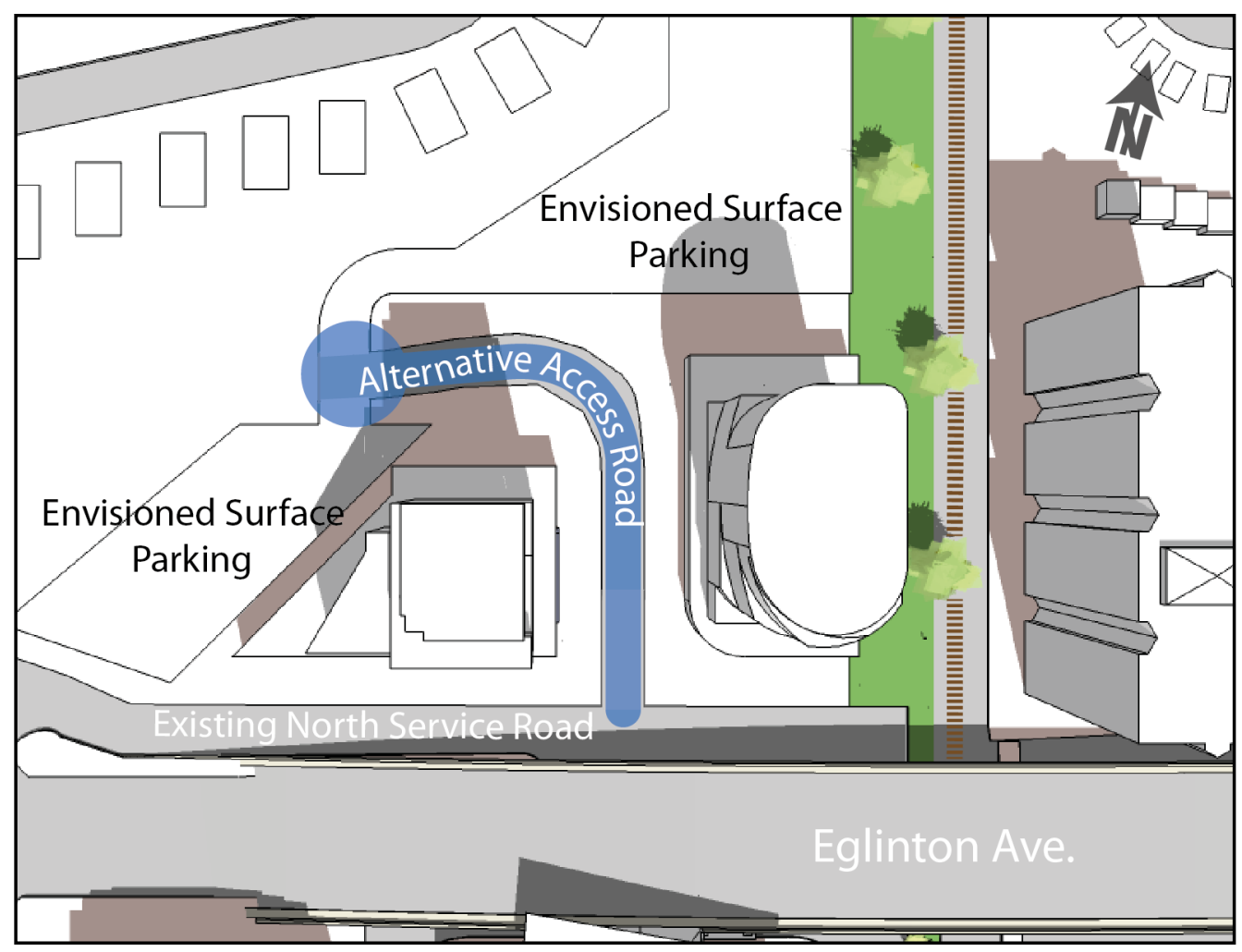

Transway Crescent, which currently provides access to the main TTC owned parking lot (South Lot) and the existing kiss-and-ride area is envisioned to be re-aligned and extended. This allows access to a new development area in the southern portion of the TTC owned 
lands. Transway Cres. Will continue to provide access to surface parking within the hydro corridor and will also allow rear access to new development fronting Eglinton Ave.

In the south-east corner of the primary zone, Truth Rd., which currently ends abruptly at the Don Montgomery Community Recreation Centre, has been extended to adjoin the southeast service road. The extension allows for access to proposed development on this Cityowned property, as well as access to the re-located kiss-and-ride facility.

Re-locating the kiss-and-ride helps allows for the creation of the South Entrance Parkette and Gatineau Recreational Trail connection (discussed below). A taxi pick-up area is envisioned adjacent to the kiss-and-ride area to replace the area where an expanded Kennedy Station is envisioned to stand.

\subsection{Site Functionality: Pedestrian Access Points}

TOD, if it is to be successful, must pay special attention to making the pedestrian experience convenient and attractive (Cervero and Kockelman, 1997; Jones, 2006; Ewing and Bartholomew, 2013). One of the ways in which the re-envisioned mobility hub seeks to achieve both of these goals is by enhancing and expanding station entrances. New and existing station entrances are highlighted in Figure 6.5. All entrances are accessed at ground level except for the new 'front' entrance which is accessed from a slightly elevated point on the Eglinton Bridge. This entrance is made possible by the re-alignment of the bus access road and creation of an enlarged station building.

Three ground-level entrances, one unchanged, one new, and one slightly altered, in addition to the elevated front entrance, provide access to the Station. Pedestrians accessing the Station from the south-west are invited to approach the Station via an extension of the Gatineau Recreational Trail running adjacent to Transway Crescent. The existing kiss-andride area to the east of the station building, which is observed to be a well-used access 
point for pedestrians coming from Kennedy Rd., has been re-located, making room for an integrated parkette and entrance point.

Figure 6.5: Station Entrances Envisioned and Existing

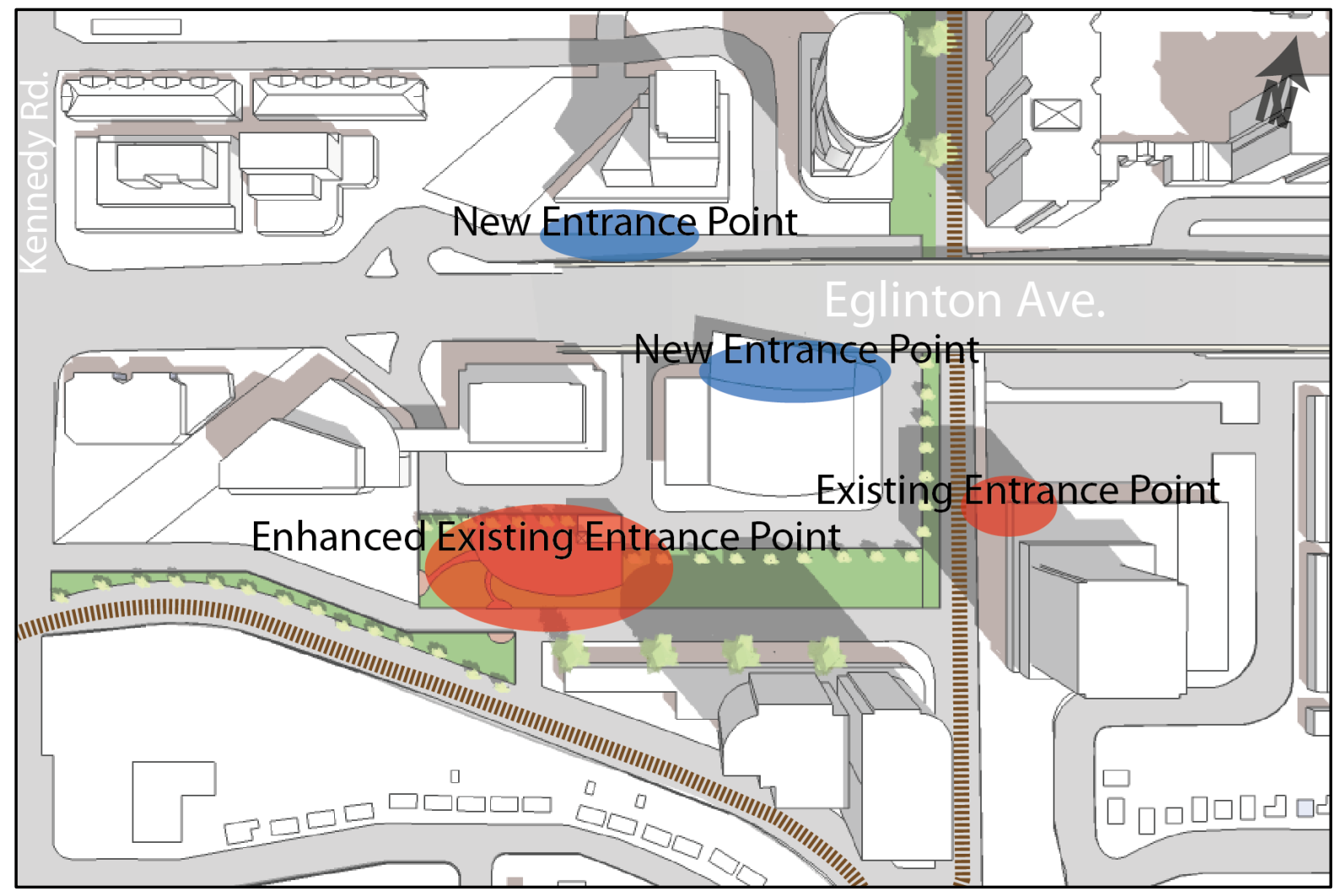

The Station's east-side entrance point near the GO platforms remains unchanged. On the north side of Eglinton Ave., an additional sub-surface entrance point is envisioned to be incorporated as part of new development, creating a convenient access point for pedestrians originating on this side of the street. This entrance will also serve as the access point for people parked in the hydro corridor surface lots and eliminate the need for a crosswalk or traffic light at the foot of the bridge, which might interfere with bus functionality.

In addition to station interface, the pedestrian experience in the primary zone will be enhanced by pedestrian-conducive urban design. New developments along Eglinton Ave. 
will front directly onto the street, facilitating the animation that can accompany ground-level retail, restaurant, and café uses. The parking lots which currently overwhelm the pedestrian experience will be replaced by underground parking or limited surface parking in the rear of buildings. Where surface parking cannot be practically re-located, such as along the hydro corridor lands, parking will be screened by trees and landscaping features.

\subsection{Site Functionality: Transit}

Busses currently access Kennedy Station via two service roads which run parallel with Eglinton Ave., as illustrated in Figure 6.6. While this design may be functionally practical from a transportation perspective, the service roads make for a somewhat awkward human experience and prevent any development directly fronting Eglinton Ave.

Figure 6.6: Present Bus Functionality

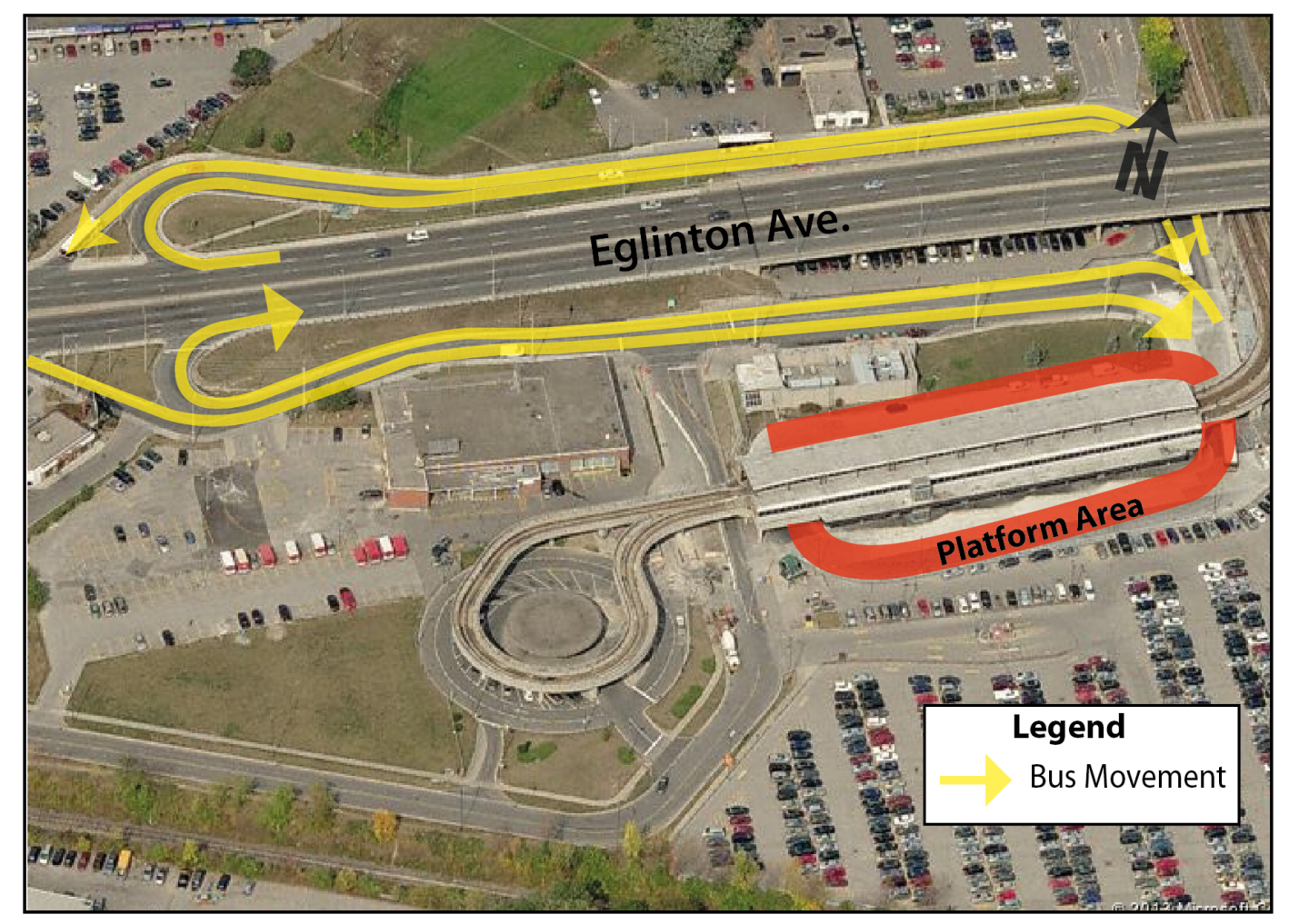

Courtesy Bing Maps, Annotations by Author 
The concept plan envisions bus access to-and-from the Station to be altered slightly from its current configuration, as illustrated in Figure 6.7. The North Service Road remains physically unchanged, while the south has been re-aligned, creating a bus route that crosses deeper into the site.

Figure 6.7 Adjusted Bus Functionality

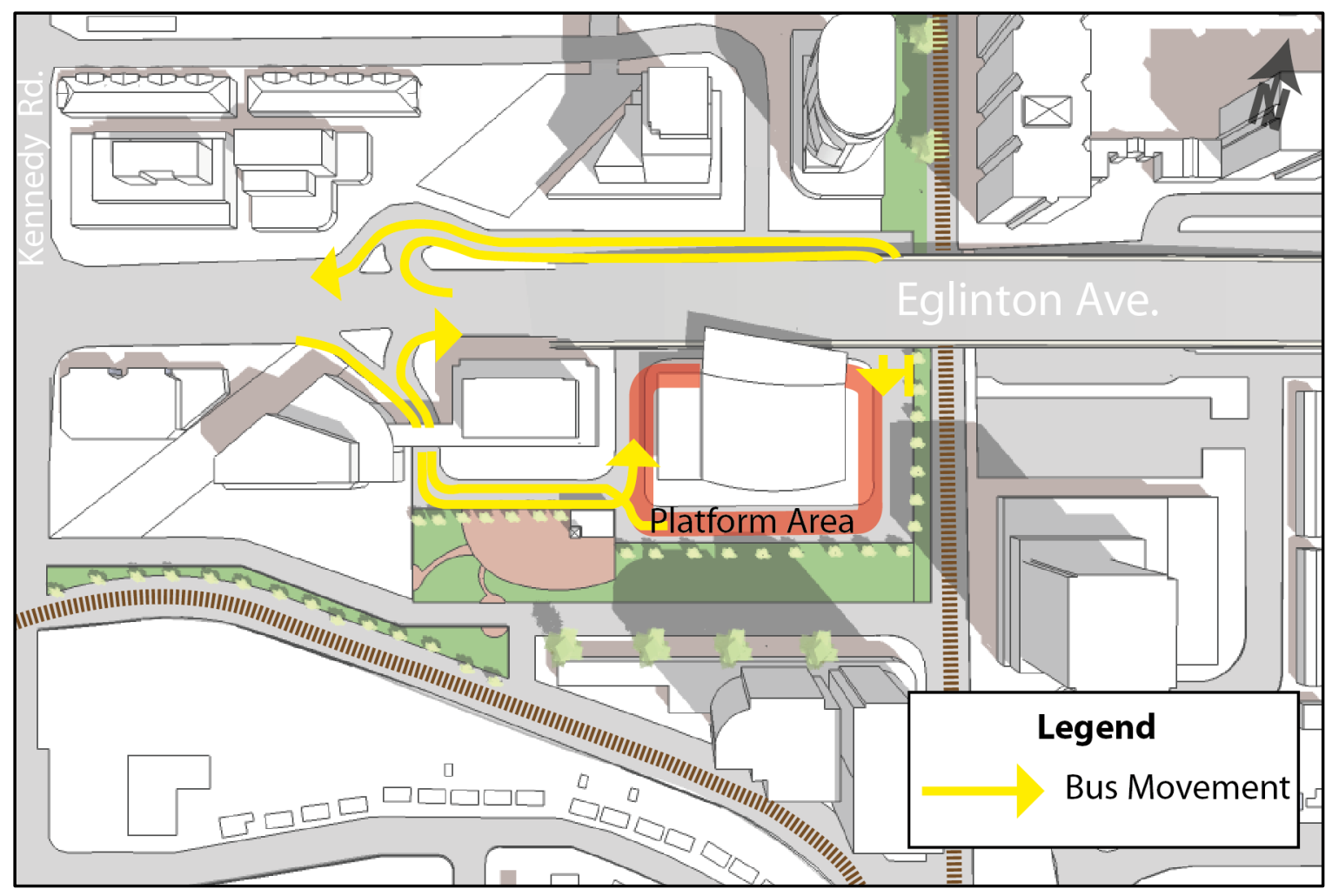

This configuration allows development on the south side of Eglinton Ave., as well as the Station itself, to be re-connected with the street. The configuration facilitates the creation of a pedestrian-accessible streetscape and viable ground-level retail. Ensuring the integrity of Eglinton Ave. on this side of the street is most critical because of the proximity to the Station. Apart from bus access, no other changes are envisioned to transit functions. The GO train platform remains as is today and the underground transit connections remain as per the project assumptions. 


\subsection{Bicycle Functionality}

Kennedy Station currently offers a number of bicycle amenities such as racks and lockers. The urban context and street network around the Station, however, is not supportive of bicyclists. The addition of bicycle lanes on Eglinton Ave. will significantly improve the mobility hub's bike-ability. The Eglinton Crosstown Project Assessment Study (2010), which only covers Eglinton Ave. to the west of Kennedy Rd., makes provisions for bike lanes along Eglinton Ave. These lanes are envisioned to be continued throughout the primary and secondary mobility hub zones. Bicycle lanes are also envisioned along Kennedy Rd. south of Eglinton Ave. to make for a safe bicycle connection to the Station's rear entrance. Expanding Bicycle storage facilities may also help encourage cycling (Pucher, 2009). The South Entrance Parkette entrance, envisioned to be the main entrance for cyclists because of its integration with the Gatineau Trail, has been sized to allow for extensive bicycle parking facilities. The remaining three entrances must also provide enough bicycle parking to comfortably meet demand, so as to be convenient for potential cyclists from all directions.

\subsection{Parking Strategy}

TOD strives to create an environment where people are enabled and inspired to walk or cycle to access transit (Cervero and Guerra, 2011). Realizing this goal would, in turn, have the effect of reducing demand for park-and-ride facilities. Economic, cultural, and political realities, however, indicate that parking will continue for the foreseeable future to be a central issue within mobility hub planning. The goal then is to minimize, as much as possible, parking's impact on the mobility hub place function and pedestrian environment.

In creating a development plan for the area, it is challenging to assert exactly how much parking should be replaced. On the one hand, parking is often at odds with creating an attractive and pedestrian-conductive environment, the kind of place where people will want to live and work. On the other, the forthcoming transit investments at this mobility hub are 
only likely to increase parking demand. Bearing in mind that political realities would make it difficult or impossible to reduce parking, this project attempts to replace all park-and-ride space. It should be noted that all new buildings are assumed to meet their own parking requirements with underground facilities.

At current, Kennedy Station provides roughly 29,000 square meters of TTC owned and operated parking (approximately 1,200 spaces). When visiting the site, it was noted that some of the TTC owned lots are, in fact, not being utilized to their full capacity. The South Lot, for example, was found to have approximately 100 out of $740(14 \%)$ spots vacant during a weekday working-hours visit and the North Service Road Lot, 90 out of 220 (41\%) spots vacant on the same occasion. Replacing (and not adding) parking, therefore, would still leave some marginal room for growth in park-and-ride service.

The envisioned configuration, illustrated in Figure 6.8, relocates a portion of the commuter parking to two new surface parking lots within the hydro corridor, and accessed by New Road $A$. The establishment of parking in this area would require the Gatineau Recreational Trail to be re-located from its current location on the west side of the corridor to the eastern edge of the corridor. Using hydro corridors for parking replacement is a strategy encouraged in the Guidelines and is currently being implemented at Islington Station in Etobicoke (Engel-Yan and Leonard, 2012). The hydro corridor presents an opportune site for the relocation parking since constructing buildings within the hydro corridor is difficult or impossible. Park-and-ride commuters would access the station building via a new entrance point on the north side of Eglinton Ave. This configuration would leave commuters with a maximum walk of about 300 meters (including the underground portion) to reach the station building. This is approximately 100 meters $(50 \%)$ longer than the existing maximum walking distance between the station building and TTC owned parking. 
Figure 6.8 Envisioned Surface and Underground Parking

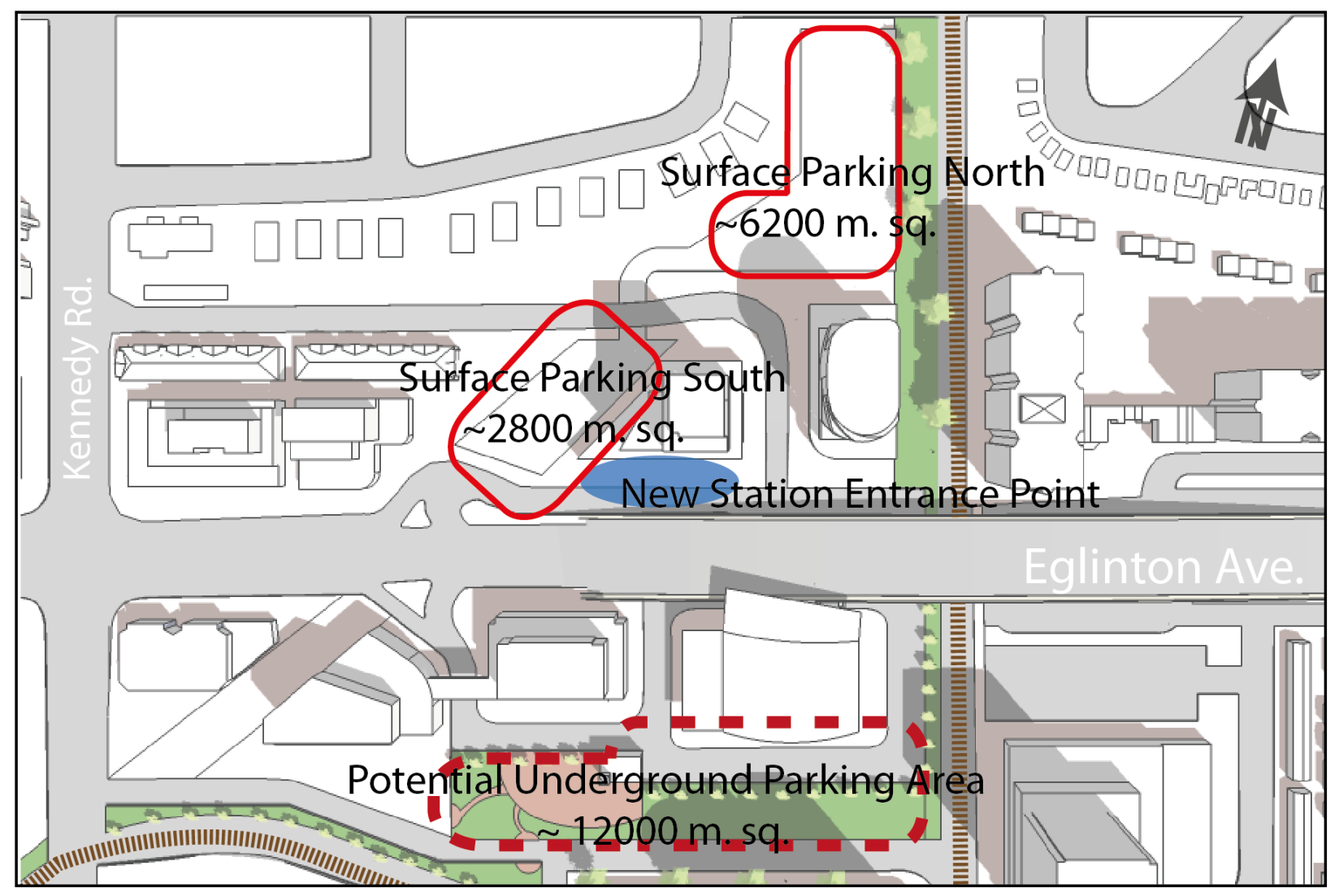

Combined, the new surface lots would provide roughly 9000 square meters of gross surface parking area, leaving a balance of 20,000 square meters to be replaced. To meet the shortfall, parking could potentially be extend further along the hydro corridor (beyond this project's boundary), however, that may be impractical given the relatively narrow corridor width. Above or below-grade parking facilities are therefore almost certainly necessary to meet demand without creating a new surface parking lot. Underground parking is the ideal choice as it allows for development or greenspace above. A preferred location for an underground parking facility dedicated to park-and-ride commuters is underneath the envisioned South Entrance Parkette and integrated Gatineau Recreational Trail. With a surface area of roughly 12,000 square meters, such a facility would need to be at least two 
levels deep to make up the parking shortfall. Whether or not such a facility would, in fact, be technically or economically feasible requires further study. An alternative to constructing a dedicated park-and-ride facility is to incorporate park-and-ride facilities as part of the subsurface parking structures associated with new developments.

Before any conclusion can be made in regards to parking provisions in the Mobility Hub, the need for parking should be assessed on a system-wide basis, as noted in the Guidelines. Nearby station areas might be able to make up for lost parking at Kennedy Mobility Hub. For example, it was observed in travelling to the site that parking was notably oversupplied at Warden Station, one stop west of Kennedy on the Bloor-Danforth subway line.

Opportunities for greater utilization, and possible expansion of parking at nearby stations, which are not mobility hubs, might alleviate some of the need for full parking replacement.

\subsection{Parkland and Recreational Greenspace}

Parkland can play an important role in fostering livability within TOD (Belzer and Autler, 2002). Furthermore, the arrival of new residents and workers into the primary zone brings with it the need for parkland and outdoor recreational space, as per the City of Toronto's Official Plan. While the mobility hub primary zone currently has no parkland, the Gatineau Recreational Trail is a valuable recreational asset for cyclists, walkers, joggers, and other users. The present terminus/access point for this section of trail is at the north-west service road, directly across from the Station. From here, the trail runs north and connects with a larger section of trail which, in turn, connects to the Don River Valley trail network. The mobility hub area re-development presents an opportunity to extend and enhance the trail, increasing both connectivity and recreational opportunities.

The envisioned trail expansion, illustrated in Figure 6.9, sees the trail re-aligning slightly to the east within the hydro corridor, the trail is envisioned to run underneath the Eglinton Ave. bridge. Heading south, the envisioned trail passes the station building, then turn to the west 
and integrates with the South Entrance Parkette. From this point, the trail runs adjacent to Transway Crescent to join with a (presently) informal trail running south-west from Kennedy Rd. adjacent to the railroad tracks. The installation of a crosswalk, stoplight, or very visible surface treatment at this point will allow for safe street crossings.

Figure 6.9 Envisioned Gatineau Recreational Trail Extension

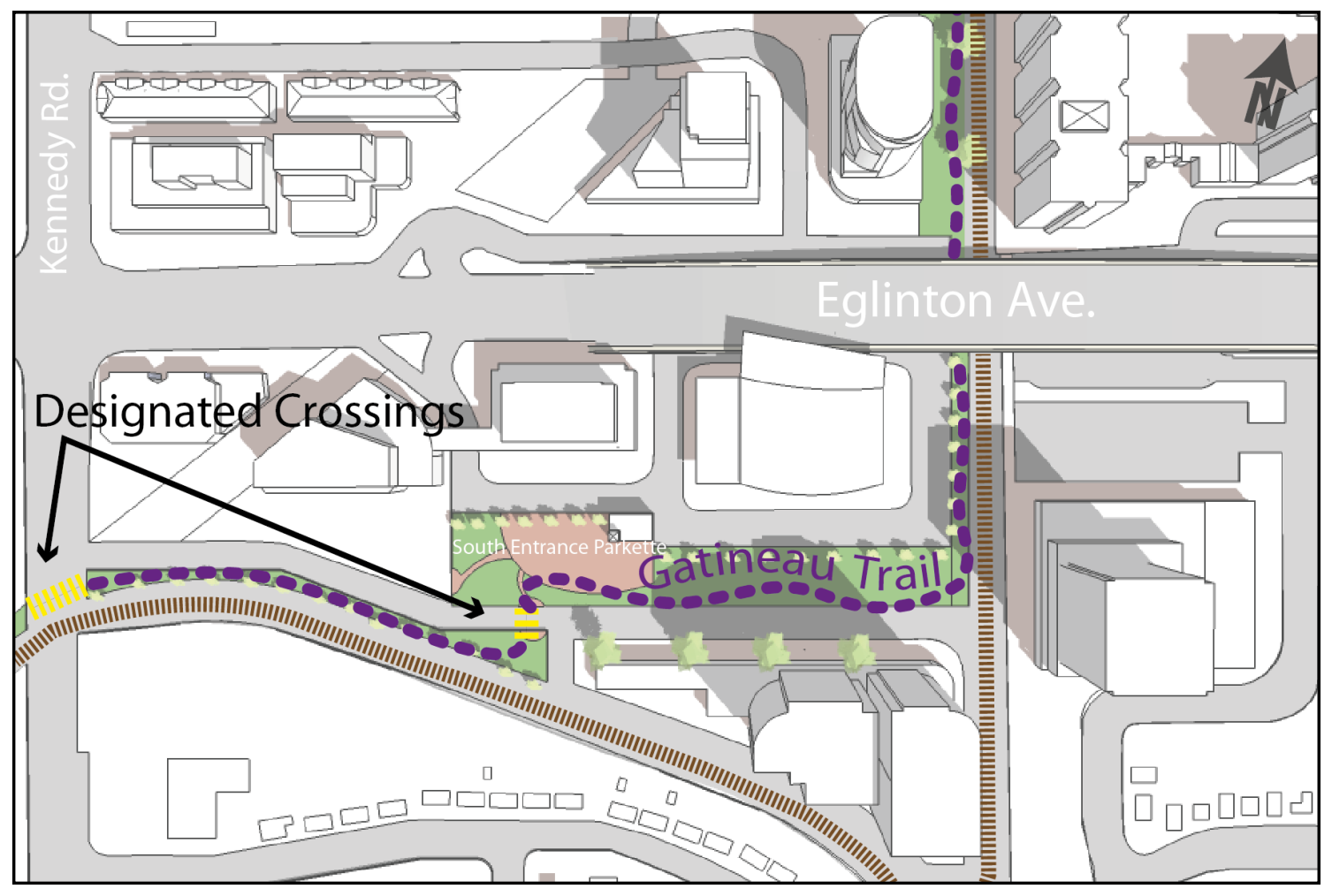

In addition to fostering livability and extending connectivity, extending and integrating the Gatineau Trail into the mobility hub is in line with the OP's policy to "connect and extend, wherever possible, to existing parks, natural areas and other open spaces" (City of Toronto, 2010, 3-5). The combined park and trail space performs another important function in buffering new development to the south from Kennedy Station's bus platform. A wall of trees and landscape screening will help attenuate the noise pollution and visual affects associated with heavy bus traffic. 


\subsection{Kennedy Station Building}

While it may be possible to continue using the existing station building after retrofitting to accommodate the new underground LRT connections, functional capacity limitations or redesign complications will likely necessitate the station building's replacement at some point. A highly conceptual vision for a new Kennedy Station, which works in conjunction with the overall site plan, is illustrated in Figure 6.10. The conceptual station design is intended to achieve two main objectives: increase bus capacity to meet anticipated service expansion, and create a "front" entrance onto Eglinton Ave.

The envisioned station has approximately two times more ground coverage than the existing facility. The additional building envelope allows for more platform area surrounding the base, providing room for future increase in bus capacity. An elevated pedestrian plaza connects the new, larger station building directly to Eglinton Ave., creating a clear and prominent front doorstep. Underneath the pedestrian plaza, busses can circulate without obstruction. Like the existing design, underground pedestrian connections avoid pedestrianbus conflicts. The increased space provided by a larger facility will allow for the incorporation of more rider amenities and retail, which increase the convenience and overall experience of taking public transit. 


\subsection{Conceptual Kennedy Station Building: Looking South-east}

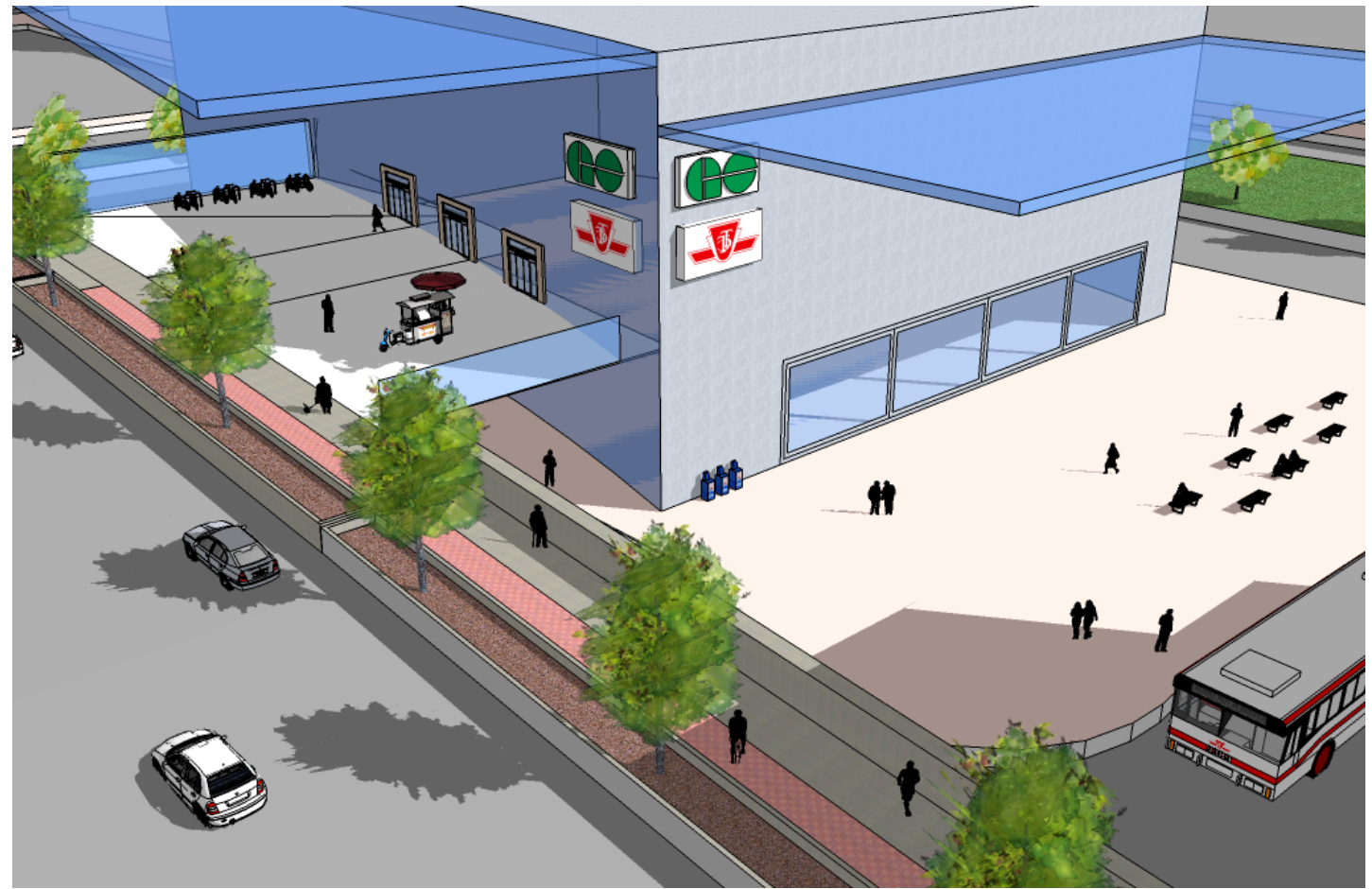

\subsection{Eglinton Avenue Bridge}

The Eglinton Ave. Bridge currently carries six lanes of motorized traffic over the $\mathrm{CN}$ railroad tracks and Scarborough RT tracks. At approximately 400 meters in length, the bridge is a physical and perceived impediment to pedestrian and cyclists. Pedestrians crossing the bridge are confined to narrow sidewalks which are shared by occasional cyclists for whom there is no lane. 


\subsection{Eglinton Avenue Bridge}

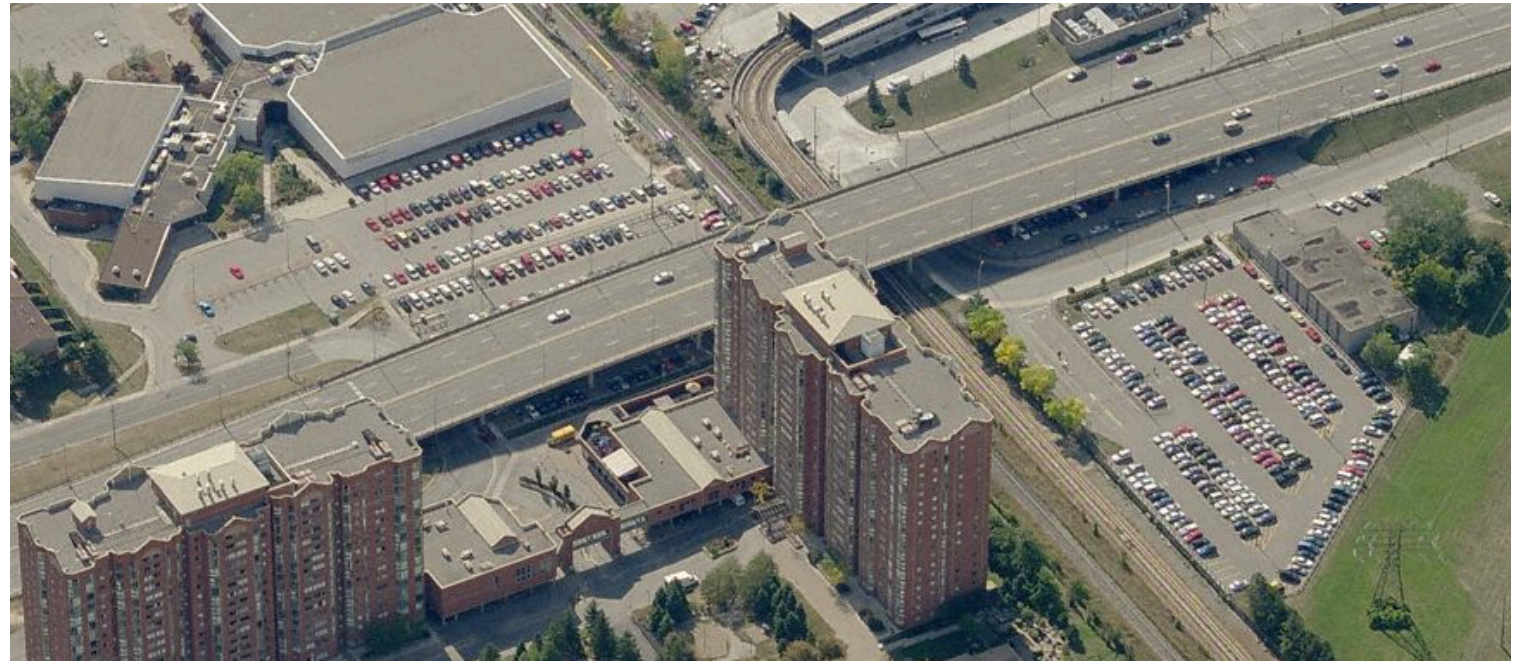

Courtesy Bing Maps

Figure 6.12 Cyclist on Bridge

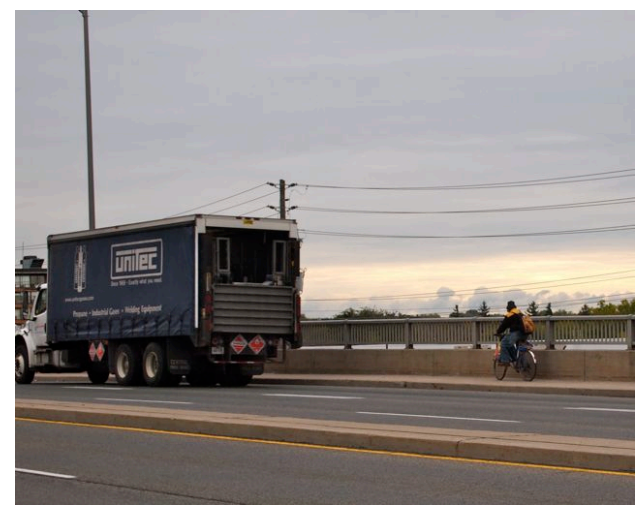

Figure 6.13 Skyline Seen From Bridge

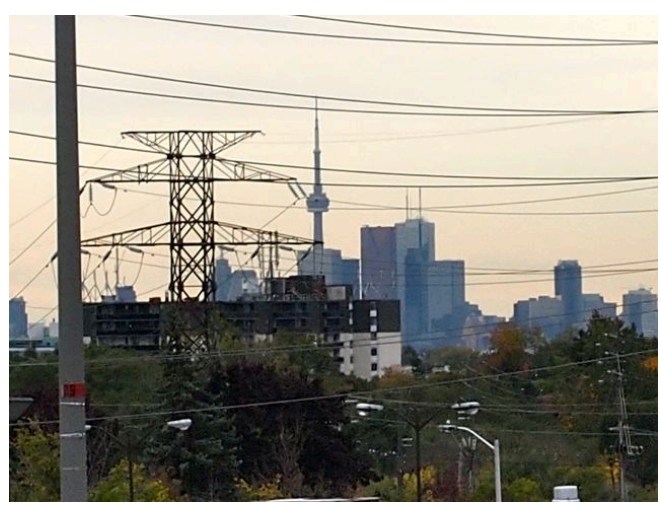

Putting aside the Bridge's effect on the pedestrian realm, the structure serves a number of necessary pragmatic functions. The structure eliminates conflict between rail and car traffic and allows for the service roads which facilitate fast and unobstructed bus movement between Eglinton Ave. and Kennedy Station. 
There are many interventions that can be taken to lessen the bridge's negative effect on the pedestrian environment. With bold enough measures, the bridge can even become a celebrated and unique feature of the Kennedy Mobility Hub. The bridge holds two major assets on which to build, the first being excellent sight-lines from its peak, including views of the city skyline and $\mathrm{CN}$ tower. The second asset is an ample amount of space which can be reconfigured to meet the Mobility Hub's future needs.

Re-appropriating a portion of car-travel space to pedestrian and bicycle space on the Eglinton Bridge will be critical to achieving the pedestrian-supportive mobility hub that is envisioned by this study. Figure 6.14 shows the bridge's current configuration, and Figure 6.15 , a conceptual re-configuration. The conceptual bridge is essentially a modified continuation of the future right-of-way west of Kennedy Rd., as per the Crosstown Transit Project Assessment Study (2010). Car travel lanes are reduced from six to four. The roughly 3 meters gained on each side is given over to a bicycle lane, which runs directly beside sidewalk, and a planted divider, separating motorized from non-motorized traffic. The divider will prevent pedestrians and cyclists from making a dangerous crossing while on the bridge as well as contribute to a more interesting pedestrian streetscape. Greenery planted in the dividers, as well as development within the greater mobility hub, should take care to preserve the south-western sight-lines. 
Figure 6.14 Eglinton Avenue Bridge Current Configuration

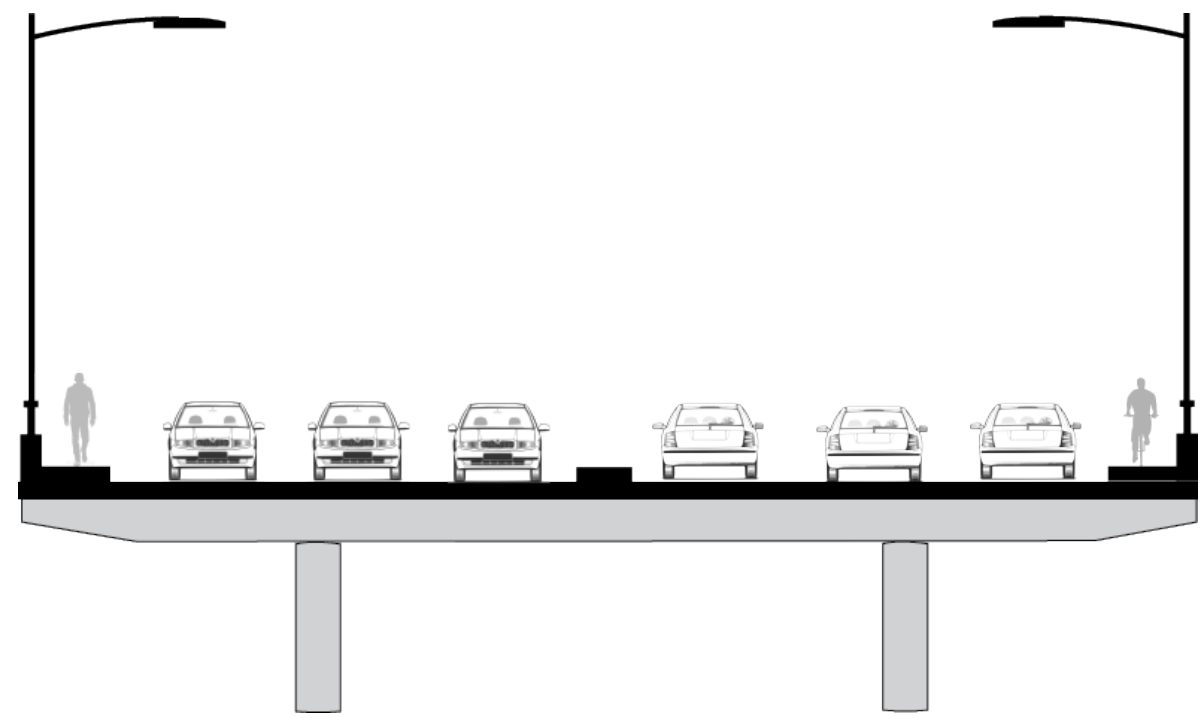

Figure 6.15 Eglinton Avenue Bridge Envisioned Configuration

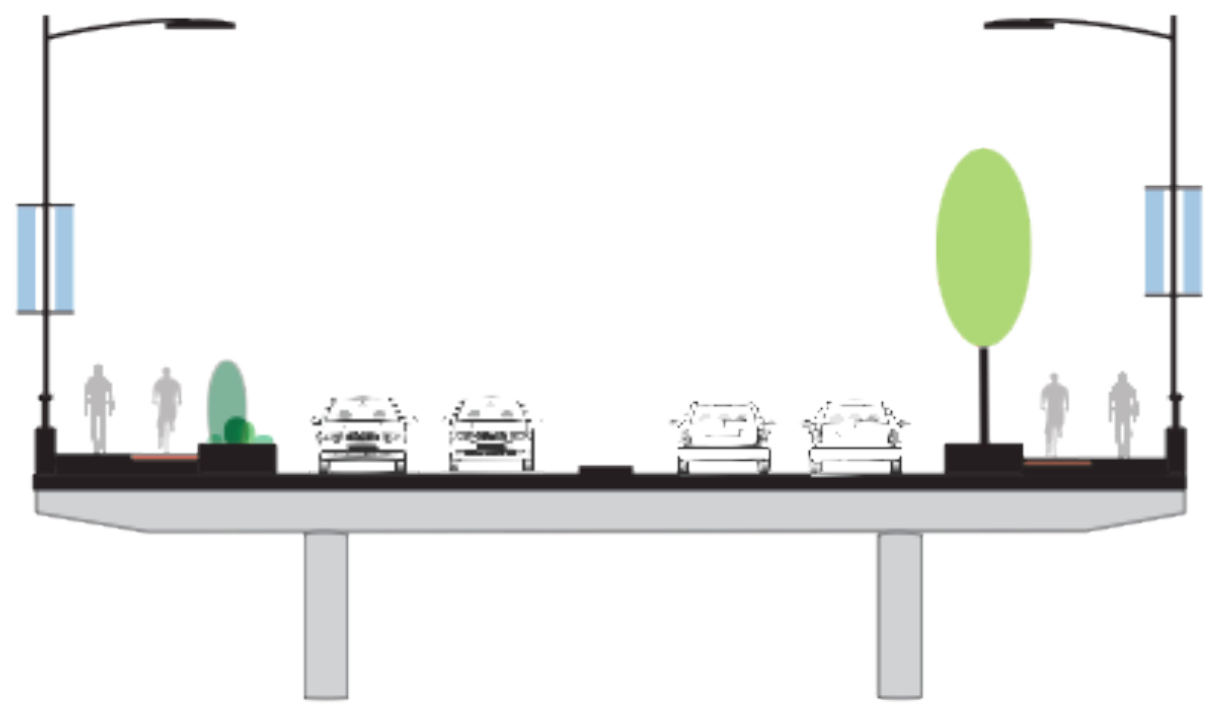




\section{Chapter 7: Potential Development Areas}

\subsection{Introduction}

As discussed in Chapter Four, Kennedy Mobility Hub currently has a combined residential and job density of approximately 7.5 per hectare, whereas minimum densities of around 60 are typically viewed by scholars as being supportive of higher-order transit (Calthorpe, 1993; Griffin, 2004; Daisa, 2003). Generating new residential and employment development in the primary zone will be critical to moving these densities towards transitsupportive levels. While intensification will not be limited to the primary zone alone, the Guidelines note that the primary zone is where "the highest intensity and mix of uses should typically be encouraged" (Metrolinx, 2011, pg.17).

Kennedy's primary zone provides a number of conditions which are ideal for new development such as underutilized lands (parking lots) and buffers between nearby stable neighbourhoods, for example the hydro corridor, and rail corridor to the south. The presence of large publicly owned lands presents an invaluable opportunity to steer the area's redevelopment and catalyze subsequent re-development of privately owned lands. This chapter will begin by discussing the considerations involved in making choices about the land uses and designs envisioned for the site. Each of the site plan's five development areas will then be presented and discussed.

\subsection{Land Use}

Establishing a healthy mix of uses near transit hubs supports a vibrant, safe, and resilient urban environment and increases the convenience of transit (Ewing and Bartholomew, 2013; Calthorpe, 1993). The envisioned re-development seeks to tightly incorporate residential, commercial and employment uses. Considering the mobility hub's current jobs 
to residents ratio of just 1-to-14 (Metrolinx, 2012), the concept plan puts a particular emphasis on employment through office development.

Though a full-scale market assessment was beyond the scope of this project, market indicators suggest that the office space market is relatively weak in this geographical area (CBRE, 2012). From a transportation and land use planning perspective, however, securing employment uses in the mobility hub is critical (Cervero, 1993). Employment uses can contribute significantly to the achievement of transit supportive densities and multidirectional transit use throughout the day. In order to bolster the potential for office development, envisioned office developments are concentrated on publicly owned lands around the Station since there is greater control over the fate of these properties. There are a number of mechanisms that could be used to ensure the achievement of these employment uses. The lands could be developed for office use by a public entity, such as Build Toronto, for example.

While at the moment office development may appear financially unfeasible in this area, office market conditions may shift in the foreseeable future. Proximity to higher-order transit is a locational asset on which employers place value, a value that is likely to grow in the near-term as congestion worsens, and the availability of inexpensive highway-adjacent land near skilled labour diminishes (Dobson et al., 2013). As the Crosstown and other higherorder investments at this site move towards completion, the viability of office development in the primary zone may increase. The concept plan's placement of office development as close as possible to the Mobility Hub's transit nucleus is intended to maximize the area's competitive advantage: virtually unparalleled access to multiple higher-order transit lines.

Commercial uses such as retail, restaurants, cafés, and the like, have also been shown to support transit (Loo et al., 2010), as well as contribute to local employment. In addition, with significant numbers of new residents and jobs planned as part of the concept plan, retail 
commercial spaces will be needed to meet their daily needs. Retail uses are envisioned as continuing their concentration along Eglinton Ave. within the first, and sometimes second, storeys of new development, thus re-enforcing the integrity of the Avenue as the area's commercial spine.

\subsection{Design}

This project does not seek to make definitive recommendations on building heights, something which would necessitate in-depth sight-lines and shadow analyses. In practice, building heights are also largely determined by market-demand, real-estate values, section 37 agreements, and numerous other factors. Assigning hypothetical building heights to envisioned developments, however, is necessary to arriving at density estimates. Buildings, therefore, have either been assigned as mid-rise or high-rise. All mid-rise buildings have an associated hypothetical height of 11 storeys, which reflects the recommended maximum for a 35 meter right-of-way as per the Avenues and Mid-Rise Building Guidelines (2010). Highrise buildings have been assigned a hypothetical height of 25 storeys, a height slightly above the directly surrounding area's largest present building(s) which are17-storeys. A note on the selection of mid-rise or high-rise accompanies each of the following development area descriptions. The buildings' architectural details are illustrative only. 
Figure 7.1 Development Areas Key

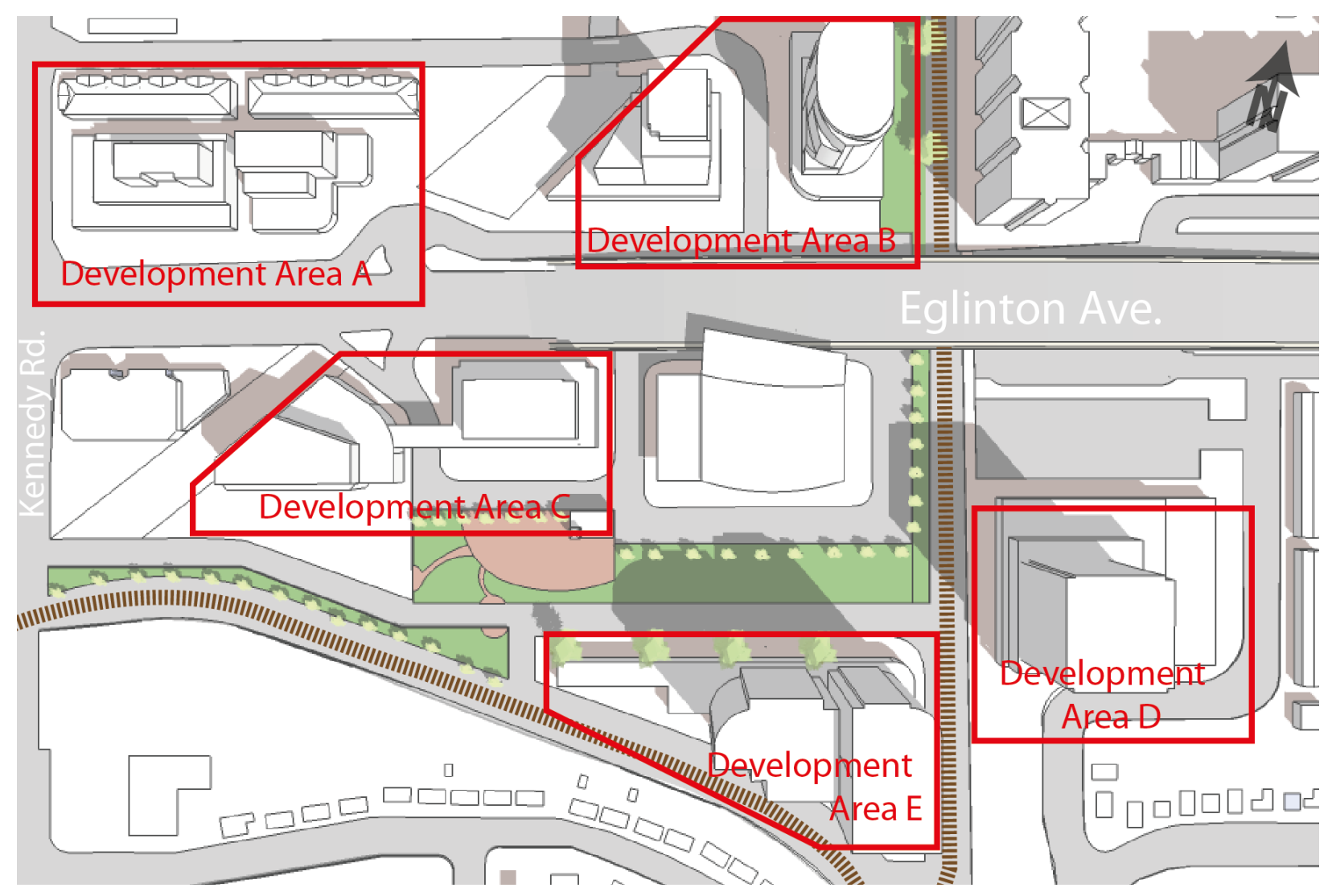




\subsection{Development Area A}

\section{Figure 7.2 Development Area A}

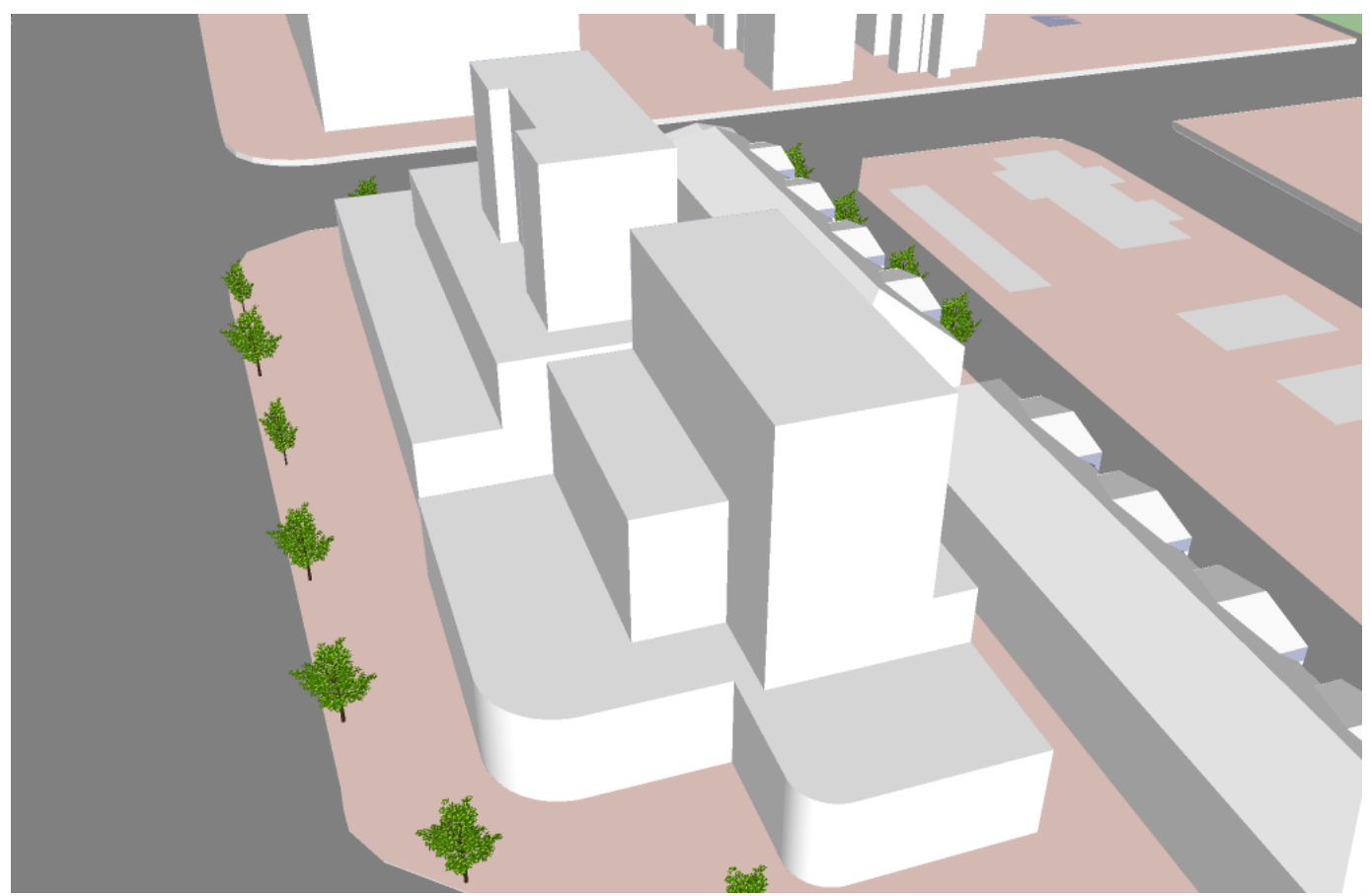

Development Area A, located at the north-east corner of Eglinton Ave. and Kennedy Rd., is currently occupied by three large, single-storey, commercial buildings. While these commercial uses, which include a bank, grocery store, and drug store, contribute positively to location-efficiency, the large parking lots and low-density built form are not pedestrian- or transit-supportive. The envisioned development for this site includes commercial use at grade that replace those currently occupying the site, and residential uses above.

Mid-rise was chosen for this site so as to respect the stable neighbourhoods directly to the north. Three storey high-density townhouses at the rear of the site, fronting onto New Road $A$, provide a gradual step-down to these neighbourhoods. As envisioned, the mid-rise portion of this development area has a gross floor space index (FSI) of 6.5, and the townhouse portion a gross FSI of 2.75 . 


\subsection{Development Area B}

\section{Figure 7.3 Development Area B}

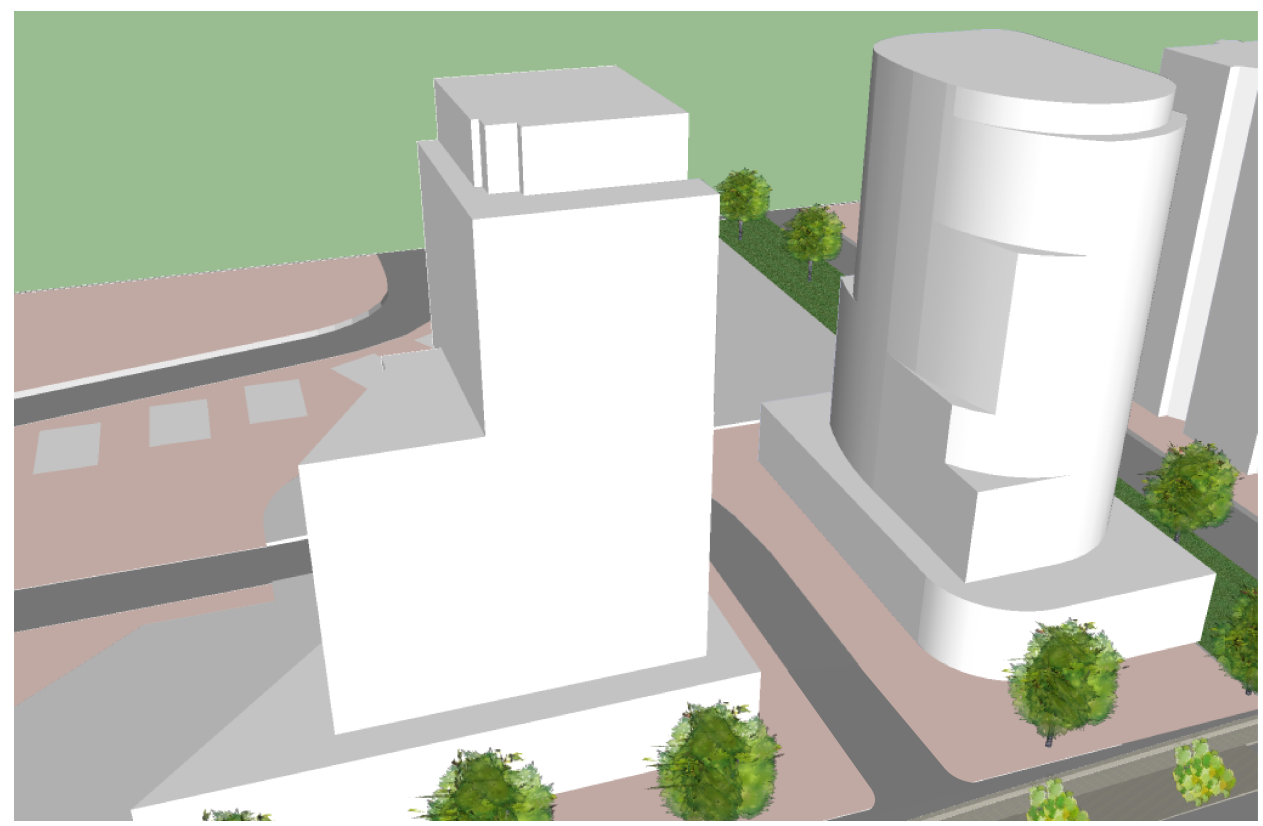

Development Area B is located directly north of Kennedy Station and is presently the TTC owned and operated North Service Road parking lot. A small portion of the site is also currently occupied by a car repair and resale business. This area is envisioned as residential development, in keeping with residential use directly to the east. A direct underground connection to Kennedy Station is envisioned to be integrated into any development on this site, providing safe and easy pedestrian access.

High-rise development is envisioned for this site because the hydro corridor creates a buffer from the neighbourhood to the north. New Road A provides servicing and access to underground parking. Elevated pedestrian connections from buildings on this site to the Eglinton Ave. Bridge would be beneficial in strengthening the integrity of the street, however, may prove impractical due to the presence of the adjacent service road. As envisioned, the developments on this site have a gross FSI of 11.5 . 


\subsection{Development Area C}

Figure 7.4 Development Area C

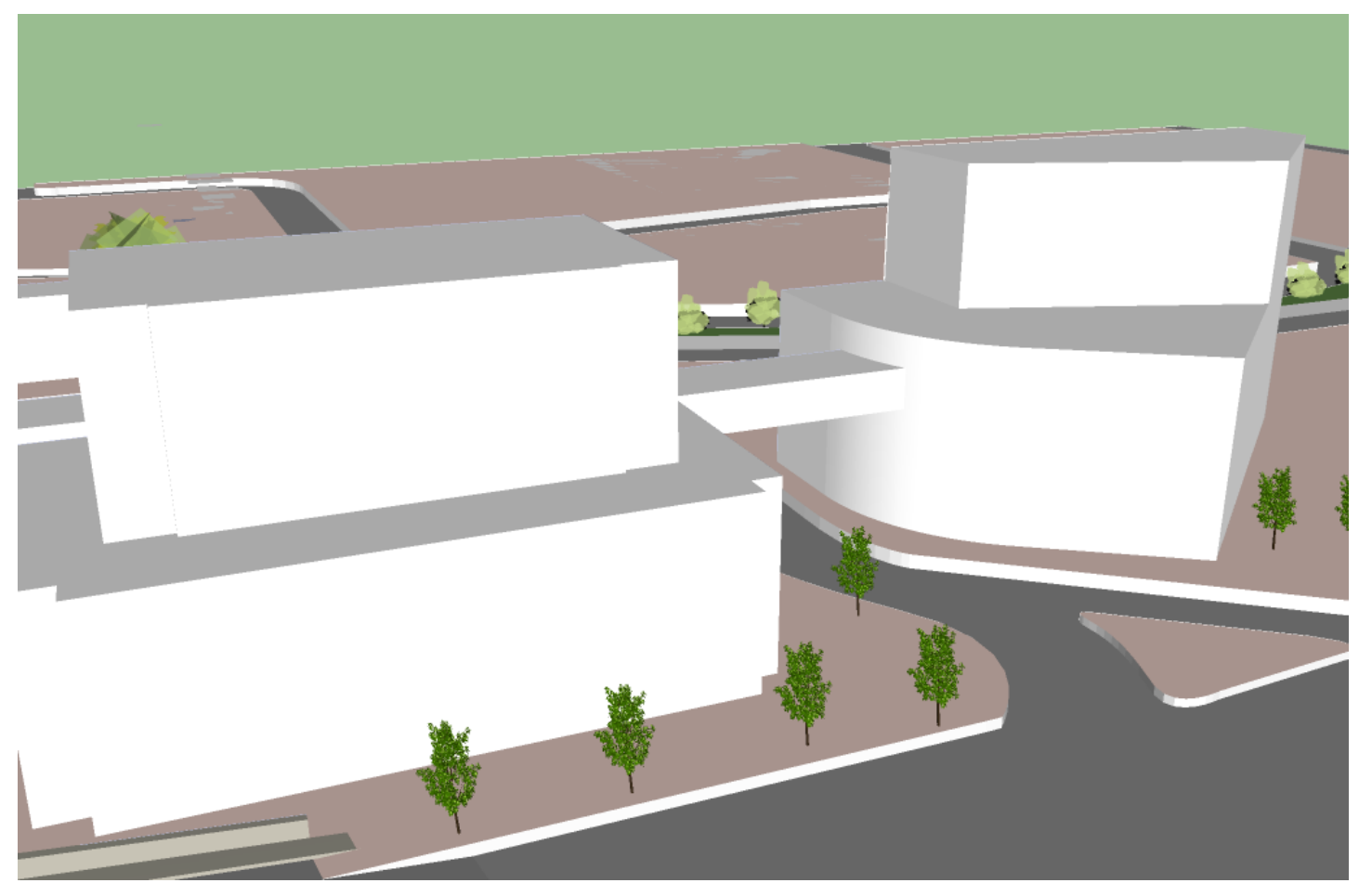

The majority of Development Area C, on the south side of Eglinton Ave., is currently a Canada Post-owned and operated facility, the majority of which is used to store delivery vehicles. A small portion of the area hosts an unoccupied building, formerly a coffee shop. The developments envisioned for this site are mid-rise, mixed use buildings, incorporating office, residential, and retail uses. The lower levels of both buildings will host an array of commercial uses that support the daily needs of transit users as well as the local community, and bring animation to the station area. Mid-rise development stepped back from the street will minimize shadow effects onto Eglinton Ave. As envisioned, development on this site has a gross FSI of 7 . 


\subsection{Development Area D}

Figure 7.5 Development Area D

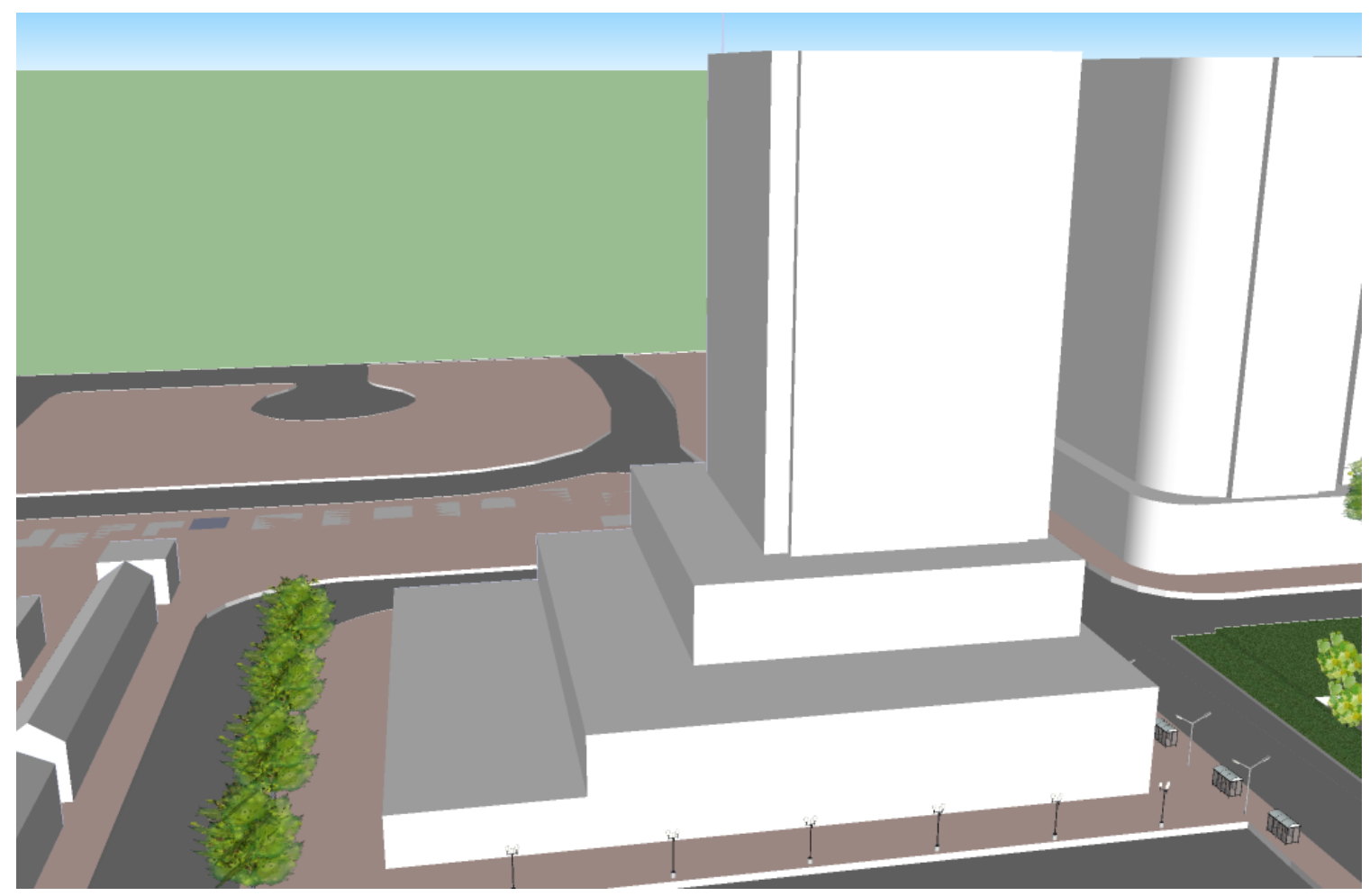

Development Area D, on the south side of Eglinton Ave., is the site of the Don Montgomery Community Recreation Centre (DMCRC), a City-owned and operated facility. The Centre is observed to be a well-used and valuable community asset, especially considering its current and future transit accessibility. This noted, about half of the site area is devoted to parking. When this facility, which opened in 1975, comes to the end of its lifespan, or it makes economic sense to do so, the City could consider re-developing this site to include residential uses while maintaining recreational uses. This could be accomplished using a partnership model such as that seen in the Regent Park or North Toronto Collegiate Institute redevelopments. 
Development on this site is envisioned to be high-rise as the considerable set-back from Eglinton Ave., (where the kiss-and-ride area is envisioned to be re-located) will minimize shadow effects on the street. This form is also consistent with the high-rise development directly adjacent. As envisioned, this development has a gross FSI of 10.5. The first four floors (or equivalent) of this development are for recreational purposes, and the remaining 21 for residential.

\subsection{Potential Development Area E}

Figure 7.6 Development Area E

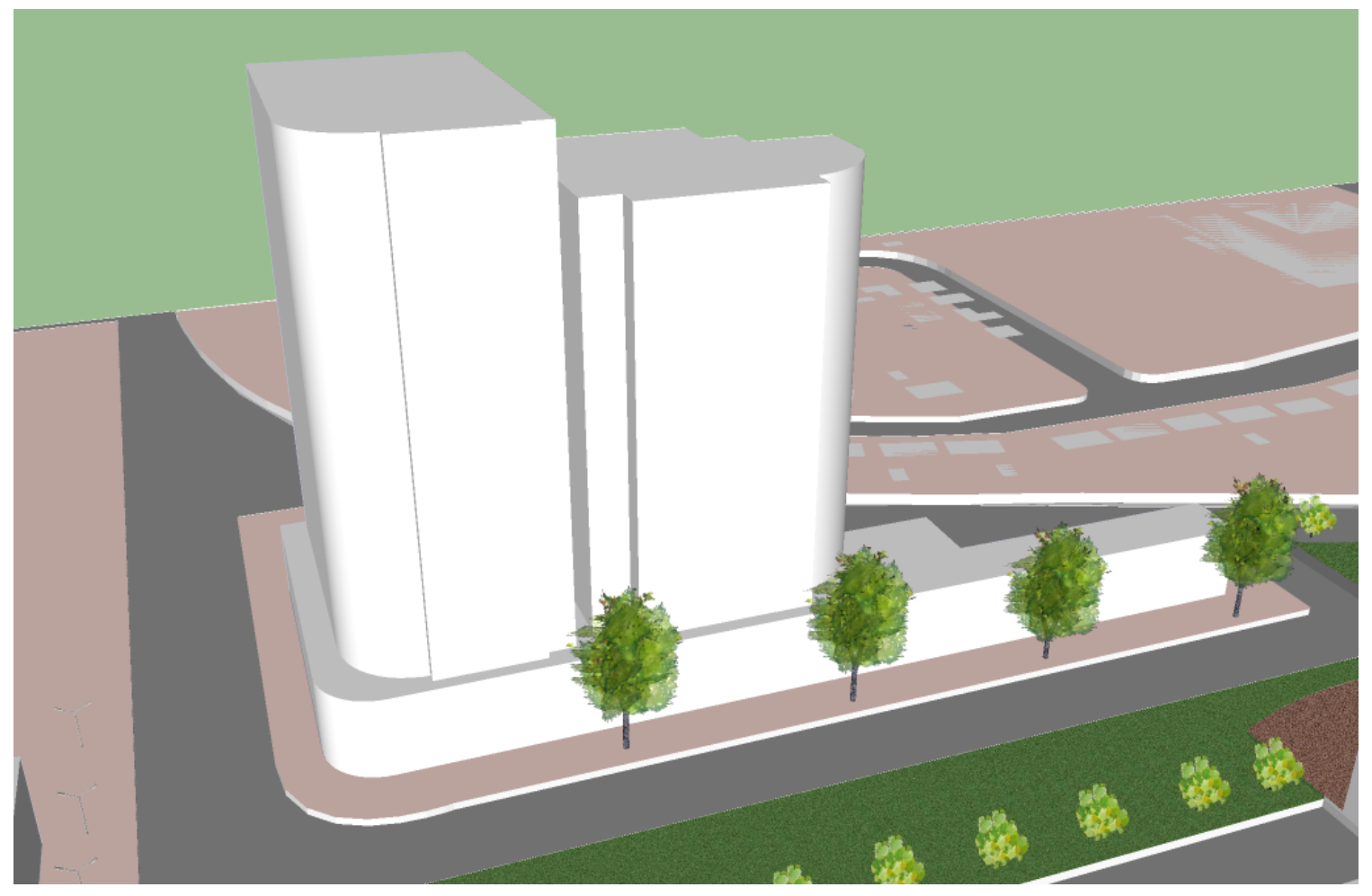

Proposed Development Area E is currently Kennedy Station's South Lot, the largest TTC owned lot in the mobility hub. This site is envisioned to be transformed into a high-rise office development, contributing significant employment density to the mobility hub. High-rise development was chosen for this site because of the rail corridors which buffer development 
from neighbourhoods to the south-east and south-west. The site and its underground parking facilities are accessible from the re-aligned Transway Crescent. As envisioned, development on this site has a gross FSI of 18 .

\subsection{Density}

By measuring the floor area for each of the hypothetical developments presented in this chapter, estimates for residential and employment densities have been calculated. The purpose of this exercise is to establish a rough understanding of the effect that such development in the primary zone would have on the Mobility Hub's density and for comparison against the goals set earlier (reflected upon in the next chapter). A detailed explanation of the method used in arriving at these numbers, as well as a breakdown for each site, is found in Appendix 2.

The additional density can be considered at two levels, first in terms of the contribution to the primary zone only, and second, in terms of contribution to the entire mobility hub area including the primary, secondary, and tertiary zones (see Section 5.1 for the delineation of these zones). The development concepts shown in this chapter have the potential to add approximately 5,200 residents, 3,400 office jobs, and 700 retail jobs to the Kennedy Mobility Hub. Strictly within the primary zone (which has an area of approximately 19.5 hectares), this would translate to a density of roughly 475 people and jobs per hectare. This level of density is quite substantial, comparable for example to Bloor-Yonge Mobility Hub (Metrolinx, 2012). It is important, of course, to remember that the primary zone is a relatively small area, making up only about one-tenth of the entire mobility hub.

When the people and jobs resulting from the concept plan's envisioned development are added to the people and jobs throughout the entire mobility hub, based on an 800 meter radius from Kennedy Station, the added density looks much less significant at 11.5 people and jobs per hectare. This is contrasted against a current ratio of 7.5 people and jobs per 
hectare (Metrolinx, 2012). In this respect the increase in density, of about $50 \%$, is only modest considering the Guidelines' general target of 50 people and jobs per hectare for Gateway mobility hubs. The increased density looks even more modest when considered against the minimum density recommendations put forth by scholars such as Calthorpe (1993), Griffin (2004), and Daisa (2003). 


\section{Chapter 8: Discussion and Conclusion}

This chapter will begin by reflecting on the goals set out in Chapter Six and commenting on any associated outcomes or findings. This will be followed by a brief discussion on any additional considerations and findings.

\subsection{Goal Reflection}

Goal 1: Increase residential and employment density to at least 60 people and jobs combined per hectare, while proposing a built form that is sensitive to surrounding neighbourhoods.

On the micro scale, the concept plan's achievement of densities over 400 people and jobs per hectare in the primary zone well exceeds the goal of at least 60 people and jobs per hectare. This level of density would facilitate the vibrancy and activity envisioned in the Guidelines and RTP. When considering the mobility hub as a whole, however, the added people and jobs result in a still-modest density within an 800 meter radius of the Station (11.5 people and jobs per hectare). This macro-level view of density is likely most logical when considering density as a means to financially support transit. It can be concluded that, at the scale of development envisioned by the concept plan, density in the primary zone alone is not sufficient to achieve transit supportive densities in the Mobility Hub.

Since adding height or massing far beyond that envisioned in the concept plan is unlikely to be sensitive to surrounding neighbourhoods, adding considerable density in the secondary zone will be essential. While there are extensive opportunities for re-development in the secondary zone, it still appears as though reaching transit-supportive densities throughout the mobility hub will be challenging. This considering the relatively modest effect of 
development in the primary zone and the expectation that development in the secondary zone would occur at a lower scale and intensity.

\section{Goal 2: Achieve a more complete mix of transit-supportive land uses.}

Achieving a transit-supportive mix of land uses is easy to achieve on paper, but may be more difficult in reality as this is, to a large degree, market-determined. The most challenging land use to establish in the primary zone would likely be employment uses. As discussed in Chapter Nine, however, market forces are constantly in flux and it is not inconceivable that the benefit associated with transit connectivity could not be used as leverage in the establishment of office employment. The establishment of residential uses should prove less challenging as it is more apparent that residents place value on transit connectivity.

The integration of retail commercial uses into the mobility hub primary zone can be accomplished through the use of ground-level retail in mid-rise and high-rise buildings. The land use inventory in Chapter Four shows a strong retail presence along Eglinton Ave., except in the primary zone where there is currently little retail space available. Considering the influx of people and jobs envisioned in the concept plan, there is little reason to think that added retail space would not be viable.

\section{Goal 3: Create a parking strategy to replace all surface parking currently on developable public lands.}

The concept plan presents a mix of options for commuter parking replacement including hydro corridor parking, underground parking facilities, and parking that is integrated into new developments. Creating surface parking within the hydro corridor is likely a costconservative way of replacing parking, however, it was found that utilizing this approach can only be used to replace a modest proportion of existing park-and-ride capacity. The narrow corridor width and desire to maintain a reasonable walking distance for park-and-ride users 
limits the usefulness of this approach. The efficacy of placing parking in a hydro corridor could also be questioned when considering that grass-covered corridors can be considered greenspaces in their own right and could be valued by surrounding communities.

Underground parking was chosen in the concept plan, to make up the shortfall left by hydro corridor parking, largely because it minimizes parking's impact on the pedestrian realm and allows for the creation of parkland above. Costs for such a project may, in reality, be prohibitive, depending on the cost recovery that could be expected and the price elasticity for commuter parking. Parking fees beyond the price threshold of park-and-ride users may weaken ridership numbers and undermine the efficacy of the mobility hub project. Before making any decisions on commuter parking, parking needs and supply should be assessed on a system-wide basis.

\section{Improve the travel experience and accessibility for pedestrians and cyclists.}

The concept plan seeks to achieve this goal by expanding and enhancing station access points and by establishing a finer-grained street network. The implementation of the entrance point improvements envisioned in the concept plan would, of course, be dependant on economic and engineering considerations. In the case of street networks, the addition of new and extended roads, for example New Road A, would be challenging to implement given the extent of land acquisition required. Meeting this challenge, however would greatly enhances the permeability and interest of the area while generating possibilities for new development.

\section{Goal 5: Identify opportunities to improve and expand parkland and greenspace.}

The redevelopment of a mobility hub primary zone can present valuable opportunities to extend existing greenspace networks, as illustrated in the concept plan. The expansion of 
the Gatineau Recreational Trail in the concept plan shows the range of objectives that greenspace network expansion can fulfil. This includes expanding non-motorized connectivity, enhancing liveability, and screening or buffering the potentially undesirable aspects of transit facilities. Greenspace can also be planned to sit atop underground transit connections, over which other development opportunities are limited.

\section{Goal 6: Ensure seamless mobility while meeting all goals.}

While the concept plan ensures mobility from a pedestrian and cyclist standpoint, through new roads and station access points, the mobility of busses might be hindered by the changes envisioned in the concept plan. For example, busses using shared right-of-ways to access the Station from Eglinton Ave. will be forced to share these roads with an increased number of private vehicles accessing parking facilities and dropping off, or picking up, passengers. This outcome may be mitigated by the introduction of new roads which can take pressure off of bus access ways. A transit priority plan, incorporating design features such as queue jump lanes and transit priority signals, as noted in the Guidelines, may also be necessary to mitigate the effects of increased traffic.

\subsection{Conclusion}

Metrolinx's vision for mobility hubs in the GTHA represents an exciting and locally unprecedented movement towards sustainability and efficiency in the region. In the case of inner-suburban commuter nodes, such as Kennedy, parking, street networks, density, and infrastructural barriers, can be anticipated as some of the most significant planning challenges. The concept plan presented in this project has put forth some potential strategies to overcome these challenges and also seeks to inspire further strategies and conversation towards transforming landscapes of parking into liveable urban environments. 
Appendix 1: Kennedy Station and Primary Zone Site Visits

\begin{tabular}{|l|l|}
\hline Date & Time \\
\hline Tuesday January $15^{\text {th }} 2013$ & $3: 00 \mathrm{pm}-4: 20 \mathrm{pm}$ \\
\hline Saturday February $9^{\text {th }} 2013$ & $1: 15 \mathrm{pm}-2: 40 \mathrm{pm}$ \\
\hline Friday March $8^{\text {th }} 2013$ & $11: 15 \mathrm{pm}-1: 15 \mathrm{pm}$ \\
\hline
\end{tabular}




\section{Appendix 2: Density Calculations}

To approximate the residents and/or jobs associated with each development site, it was first necessary to determine the total floor area for each building. The buildings, made and measured in Google Sketchup modelling software, were separated into their geometrical components, envelopes measured, then multiplied by the associated number of storeys. Total floor area was multiplied by $85 \%$ to account for unusable (un-sellable) space, or "gross-to-net efficiency." $85 \%$ is a commonly used rule-of-thumb, often seen in development pro formas (see for example, Kozac, 2005).

In the case of residential use, total usable floor area was divided by the City of Toronto's average condominium size of 76 meters (CBC, 2012), to arrive at the number of units. The number of units was then multiplied 2.8 , the average household size in the mobility hub (Metrolinx, 2012).

In the case of office space, usable floor area was multiplied by .0344 , the number of office employees per meter for "general office use" (Ewing and Bartholomew, 2013). A similar method was used to calculate retail jobs, however, because these retail uses could take an array of different forms (grocery stores, discount stores, restaurants, banks, etc.) which have different employee space requirements, a composite was created. The composite, based on Ewing and Bartholomew's (2013) employee space estimates for banks, sit-down restaurants, and discount stores, were given equal weight to arrive at .055 employees per meter. In the case of Development Area A, where retail exists currently, new retail was assumed only to replace existing retail, contributing therefore no net retail change. 


\section{Table 1: Basic Building and Density Assumptions}

\begin{tabular}{|l|r|}
\hline Building Assumptions & \\
\hline Height per Floor (m.) & 3 \\
\hline Gross-to-Net Efficiency For all Building Types & $85 \%$ \\
\hline & \\
\hline Residential Assumtions & \\
\hline & \\
\hline Average size per Residential Unit (m. square) & 76 \\
\hline Average residents per Unit & 2.8 \\
\hline Meters per resident (m. square) & 27.14286 \\
\hline & \\
\hline Employment Assumtions & \\
\hline Office Workers Per Meter & 0.0344 \\
\hline Retail employees per meter & 0.055 \\
\hline Meters per Retail Employee & 46 \\
\hline
\end{tabular}

\section{Table 2: Development Area A}

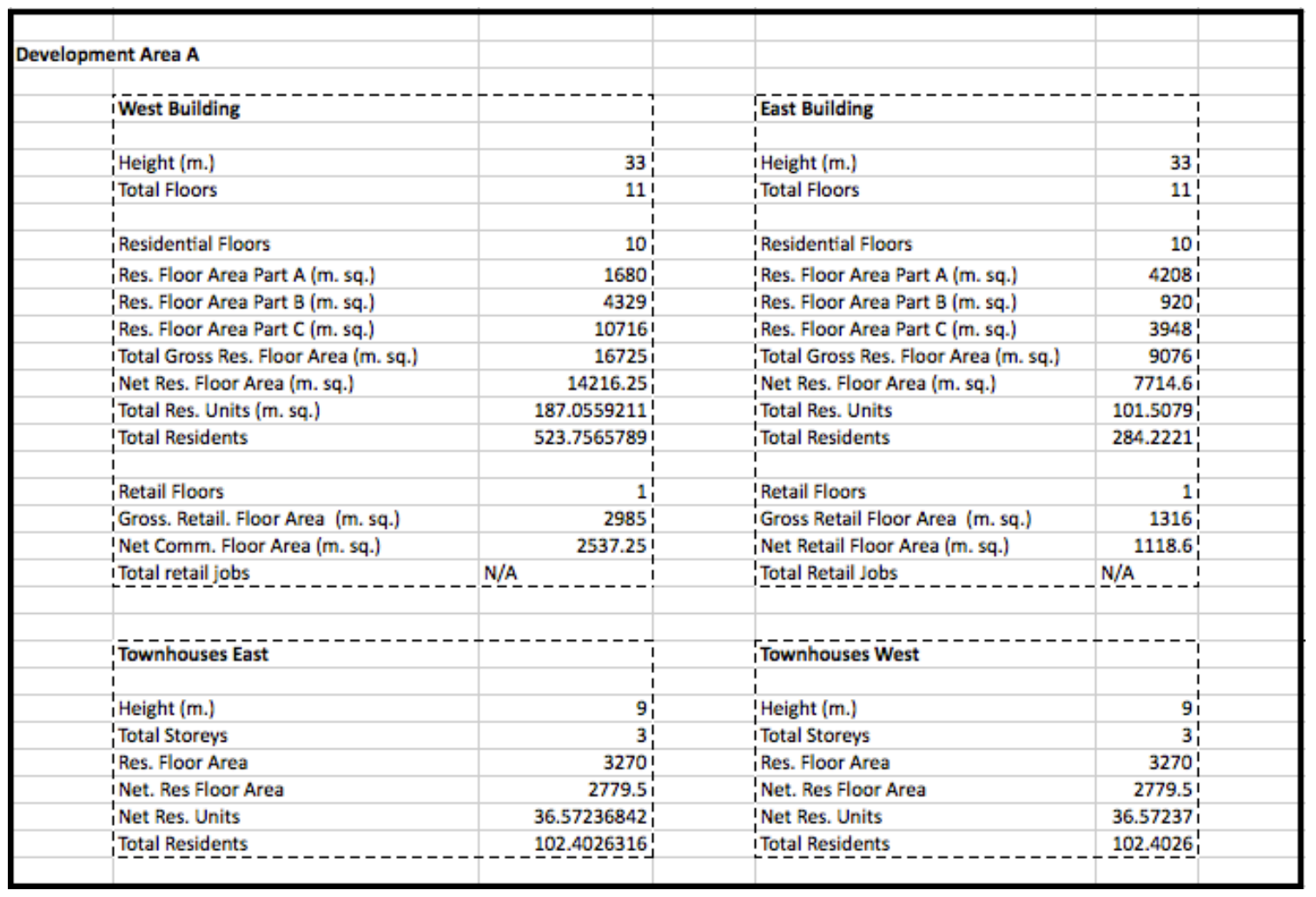


Table 3: Development Area B

\begin{tabular}{|c|c|c|c|}
\hline \multicolumn{4}{|l|}{ Development Area B } \\
\hline 'West Building $-\overline{-}$ & $-\frac{1}{1}$ & East Building & \\
\hline i & i & i & 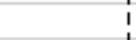 \\
\hline Height (m.) & 751 & Height (m.) & $75 i$ \\
\hline Total Floors & $25 !$ & Total Floors & $25 !$ \\
\hline i & 1 & i & i \\
\hline IRetail Floors & 11 & Retail Floors & $1 !$ \\
\hline 'Gross Retail Floor Area & $2346 !$ & Gross Retail Floor Area & $2687 !$ \\
\hline Net Retail Floor Area & $1994.1 !$ & Net Retail Floor Area & 2283.95 । \\
\hline Retail jobs & 109.6755 & Retail Jobs & 125.6173 \\
\hline 1 & 1 & i & 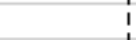 \\
\hline 'Residential Floors & $24 !$ & 'Residential Floors & $24 i$ \\
\hline Residential Floor Area Part A (m. sq.) & 7038 & Residential Floor Area A & 8061 । \\
\hline Residential Floor Area Part B (m. sq.) & $1130 !$ & 'Residential Floor Area B & $25851_{1}^{i}$ \\
\hline Residential Floor Area Part C (m. sq.) & $15181 i$ & Gross Residential Floor Area Total & $33912 !$ \\
\hline Residential Floor Area Part D (m. sq.) & 3792 & Net Residential Floor Area & 28825.2 \\
\hline Gross Retail. Floor Area (m. sq.) & $27141^{\prime}$ & Total Residential Units & 446.2105 \\
\hline Net Residential Floor Area & $23069.85 !$ & Total Residents & 1249.389 \\
\hline Total Residential Units & $303.5506579 !$ & 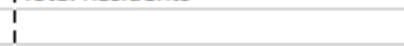 & 1 \\
\hline Total Residents & 849.9418421 & 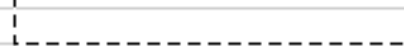 & \\
\hline
\end{tabular}

Table 4: Development Area C

\begin{tabular}{|c|c|c|c|}
\hline Development Area C & & & \\
\hline T'West Building & 1 & 'East Building & i \\
\hline i & i & 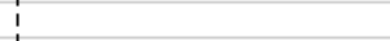 & i \\
\hline 'Height (m.) & $33 i$ & Height (m.) & $33 !$ \\
\hline iTotal Floors & 111 & Total Floors & 111 \\
\hline i & 1 & 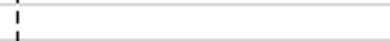 & i \\
\hline Retail Floors & $2 i$ & Retail Floors & $2\}$ \\
\hline Gross Retail Floor Area (m.sq.) & $4300 !$ & Gross Retail Floor Area (m. sq.) & $4984 !$ \\
\hline I Net Retail Floor Area(m.sq.) & $3655 i$ & Net Retail Floor Area (m. sq.) & 4236.41 \\
\hline Total Retail Jobs & 201.025 i & Total Retail Jobs & $233.002 i$ \\
\hline i & $i$ & 1 & i \\
\hline Office Floors & 41 & Office Floors & $4 !$ \\
\hline IGross Office Floor Area (m.sq.) & 86001 & Gross Office Floor Area (m. sq.) & 99681 \\
\hline Net Office Floor Area (m.sq.) & $7310 !$ & 'Net Office Floor Area (m. sq.) & 8472.81 \\
\hline Total Office Jobs & $251.464 !$ & ITotal Office Jobs & $291.4643 !$ \\
\hline i & 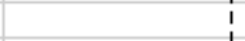 & 1 & i \\
\hline IResidential Floors & $5 i$ & Residential Floors & $5 i$ \\
\hline Residential Floor Area (m.sq.) & 1174 & Gross Residential Floor Area & 5560 \\
\hline Gross Residential Floor Area Total (m.sq.) & $5870_{1}^{1}$ & I Net Res. Floor Area (m. sq.) & $4726 !$ \\
\hline Net Residential Floor Area (m.sq.) & $4989.5 !$ & Total Res. Units (m. sq.) & $62.18421 !$ \\
\hline ITotal Residential Units & 65.65131579 & Total Residents & 174.1158 \\
\hline Total Residents & 183.8236842 & 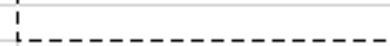 & - $-\ldots$ \\
\hline
\end{tabular}


Table 4: Development Area D

\begin{tabular}{|l|r|r|}
\hline \multicolumn{2}{|l|}{ Development Area D } \\
\hline & Height (m.) & \\
\hline Total Floors & 75 & \\
\hline & 25 & 21 \\
\hline Residential Floors & 24675 & 16944 \\
\hline Res. Floor Area Part A (m. sq.) & 41619 \\
\hline Res. Floor Area Part B (m. sq.) & 35376.15 \\
\hline Total Gross Res. Floor Area (m. sq.) & 465.4756579 \\
\hline Net Res. Floor Area (m. sq.) & 1766.962105 \\
\hline Total Res. Units & & 4 \\
\hline Total Residents & 11475 \\
\hline & & \\
\hline Rec. Centre Equiv. Floors & \\
\hline Rec. Ctr. Floor Area Equiv. (m. sq.) & \\
\hline
\end{tabular}

Table 5: Development Area E

\begin{tabular}{|c|c|}
\hline Development Area E & \\
\hline Height (m.) & 75 \\
\hline Total Floors & 25 \\
\hline Office Floor Area Part A (m. sq.) & 43575 \\
\hline Office Floor Area Part B (m. sq.) & 36575 \\
\hline Office Floor Area Part C (m. sq.) & 17432 \\
\hline Gross Office Floor Area (m. sq.) & 97582 \\
\hline Net Office Floor Area (m. sq.) & 82944.7 \\
\hline Total Office Jobs & 2853.29768 \\
\hline
\end{tabular}




\begin{tabular}{|l|r|r|}
\hline New People and Jobs Summation & \\
\cline { 1 - 1 } & Total New Residents & \\
& & 3237.016842 \\
\hline New Office Jobs & 669.31975 \\
\hline New Retail Jobs & 4065.54575 \\
\hline Total New Jobs & \\
\hline & & 9302.562592 \\
\hline
\end{tabular}

Table 7: Existing and New People and Jobs Summarized

\begin{tabular}{|l|r|}
\hline People Existing & 14000 \\
\hline Add'I People & 4054 \\
\hline Total People & 18054 \\
\hline & \\
\hline Jobs Existing & 1000 \\
\hline New Office Jobs & 3400 \\
\hline New Retail Jobs & 700 \\
\hline Total Jobs & 5100 \\
\hline & \\
\hline Total People and jobs & 23154 \\
\hline Total People and Jobs/ ha. & 11.5158549 \\
\hline
\end{tabular}




\section{References}

Belzer, D. and Autler, G.(2002).Transit Oriented Development: Moving from Rhetoric to Reality. A Discussion Paper Prepared for The Brookings Institution Center on Urban and Metropolitan Policy and The Great American Station Foundation.

Bertolini, L. (1998). Station Area Redevelopment in Five European Countries: An International Perspective on a Complex Planning Challenge. International Planning Studies, 3(2), 163-183.

Bowman, M. (2012) Addressing Challenges to Mobility Hub Implementation at Suburban Commuter Rail Parking Lots in Greater Toronoto. (Master's MRP). Ryerson University, Toronto, ON.

Calthorpe, P. (1993). The Next American Metropolis: Ecology, Community and the American Dream. New York: Princeton Architectural Press.

Carlton, I. (2007). Histories of Transit-Oriented Development: Perspectives on the Development of the TOD Concept. University of California, Berkeley. Retrieved from http://www.iurd.berkeley.edu/publications/wp/2009-02.pdf.

CBC. (2012). Toronto's new condo mix. Retrieved from http://www.cbc.ca/news/interactives /toronto-newcondos/

CBRE Global Research Consulting. (2012). Office Marketview: Toronto. Retrieved from http://www.cbre.ca/AssetLibrary/national4q12ofc.pdf

Cervero, R. (1993). Ridership Impacts of Transit-Focused Development in California. Report to The California Department of Transportation and The University of California Transportation Center.

Cervero, R. (2006). Office Development, Rail Transit, and Commuting Choices. Journal of Public Transportation, 9(5), 41-55.

Cervero, R. and Guerra, E. (2011). Urban Densities and Transit: A Multi-Dimensional Perspective. Institute of Transportation Studies, University of California Berkeley. 
Cervero, R. and Guerra, E. (2011). Urban Densities and Transit: A Multi-dimensional Perspective. UC Berkeley Institute of Transportation Studies.

Cervero, R., Adkins, A., \& Sullivan, C. (2010). Are Suburban TODs Over-Parked? Journal of Public Transportation, 13 (2), 47-70.

Cervero, R., and Kockelman, K. (1997). Travel Demand and the 3D's: Density, Diversity, and Design. Transportation Research, 2(3), 199-219.

City of Toronto. (2010). Avenues and Mid-Rise Buildings Study. Retrieved from http://www.toronto.ca/planning/midrisestudy.htm

Cochrane, G. (2005). Glenn Cochrane's Toronto. ECW Press: Toronto.

Dobson et al. (2013). Strategic Regional Research: A Region in Transition. Retrieved from http://www.canurb.com/cui-news/new-report-by-strategic-regional-research-a-regionin-transition.html

Duncan, M. (2010). To Park or To Develop: Trade-Off in Rail Transit Passenger Demand. Journal of Planning Education and Research, 30(2), 162-181.

Dunphy, R. and Porter, D. (2006). Manifestations of Development Goals in TransitOriented Projects.

Engel-Yan, J. and Leonard, A. (2012). Mobility Hub Guidelines: Tools for Achieving Successful Station Areas. Institute of Transportation Engineers Journal, 42-47.

Ewing, R and Cervero, R. (2010). Travel and the Built Environment: A Meta-Analysis. Journal of the American Planning Association, 76 (3), 265-294.

Filey, M. (1996). The TTC Storey: The First Twenty-Five Years. Dundurn Press: Toronto. Filion, P. (2006). The Mixed Success of Nodes as a Smart Growth Planning Policy. Environment and Planning B: Planning and Design, 36, 505-521.

Griffin, K. (Ed.). (2004). Building Type Basics for Transit Facilities. Hoboken, NJ: John Wiley \& Sons.

Jones, B. (2006). Feasibility Report for a Network of New Mobility Hubs in the Toronto Region. 
Kozac, A. (2005). Mid-Rise Economics, Proforma Analysis. Retrieved from http://www.t oronto.ca/planning/pdf/midrise_proforma_midvshigh.pdf

Loo et al. (2010). Rail-based transit-oriented development: Lessons from New York City and Hong Kong. Landscape and Urban Planning, 97, 202-212.

Metrolinx. (2008).The Big Move. Retrieved from http://www.metrolinx.com/thebigmove/ Docs/big_move/TheBigMove_020109.pdf

Metrolinx. (2011). Mobility Hub Guidelines. Retrieved from http://www.metrolinx.com/ en/docs/pdf/ board_agenda/20110218/MobilityHubGuidelines_optimized.pdf

Metrolinx. (2012). Mobility Hub Profiles. Retrieved from http://www.metrolinx.com/ mobilityhubs/en/map/mobility_hubs_map/MHP_Kennedy.pdf

Morris, M. (1996). Creating Transit-Supportive Land use Regulations. Chicago, IL: American Planning Association.

Pucher, J. (2009). Integrating Bicycling and Public Transport in North America. Journal of Public Transportation, 12(3), 79-104.

Toronto Transit Commission. (2010). Scarborough-Malvern Light Rail Transit. Retrieved from http://www.toronto.ca/involved/projects/malvern_Irt/

Toronto Transit Commission. (2010). Toronto Transit Commission Subway Ridership, 20092010. Retrieved from http://www.ttc.ca/PDF/Transit_Planning/Subway\% 20ridership\%202011-2012.pdf

Toronto Transit Commission. (2013). TTC Milestones. Retrieved from http://www.ttc.ca/ About_the _TTC/History/Milestones.jsp

Toronto Transit Commission. (2013). Kennedy Station. Retrieved from http://www.ttc.ca/ /Stations/Kennedy/station.jsp

Toronto Transit Commision and Metrolinx. (2010) Eglinton Crosstown Light Rail Transit: Transit Project Assessment Study. Retrieved from http://www.thecrosstown.ca/theproject/the-plan/environmental-assessments

Toronto Transit Commission and URS Corporation. (2010). Scarborough Rapid Transit 
Environmental Project Report. Retrieved from http://www.toronto.ca/involved/projects /scarborough_rapid_transit/index.htm

Transit Research Board of National Academics. (2004). Transit-Oriented

Development in the United States: Experiences, Challenges, and Prospects.

Retrieved from http://onlinepubs.trb.org/onlinepubs/tcrp/tcrp_rpt_102.pdf

Transit Toronto. (2005, June 01). GO Welcomes Customers to New Kennedy GO Station in Scarborough ON. [Web log comment]. Retrieved from http://transit.toronto.on.ca/ archives /data/200506011544.shtml

Tumlin, J., and Millard-Ball, A. (2003). How to Make Transit-Oriented Development Work. Transportation Research, 2(3), 199-219.

Unterman McPhail Associates. (2010). Cultural Heritage Resource Assessment Report: Built Heritage and Cultural Heritage Landscapes. Retrieved from http://www.toronto.ca /involved/projects/eglinton_crosstown_Irt/epr/appendixccultural-heritage-resource-assessment-report.pdf 